\title{
Nanomedicines as Cancer Therapeutics: Current Status
}

\author{
Sohail Akhter ${ }^{1, *}$ Iqbal Ahmad ${ }^{2,}$ Mohammad Zaki Ahmad ${ }^{3}$, Farshad Ramazani ${ }^{1}$, Anjali Singh², \\ Ziyaur Rahman ${ }^{4}$, Farhan Jalees Ahmad ${ }^{2}$, Gert Storm ${ }^{1,5}$ and Robbert J. Kok ${ }^{1}$
}

\author{
${ }^{I}$ Department of Pharmaceutics, Department of Pharmaceutical Sciences, Utrecht University, Universiteitsweg 99,3584 \\ CG, Utrecht, The Netherlands; ${ }^{2}$ Nanomedicine Research Lab, Department of Pharmaceutics, Faculty of Pharmacy, \\ Jamia Hamdard, New Delhi 110062, India; ${ }^{3}$ Department of Pharmaceutics, College of Pharmacy, Najran University, \\ Kingdom of Saudi Arabia; ${ }^{4}$ Irma Lerma Rangel College of Pharmacy, Texas A\&M Health Science Center, Kingsville, \\ Texas, USA; ${ }^{5}$ Department of Targeted therapeutics, MIRA Institute for Biomedical Technology \& Technical Medicine, \\ University of Twente, Drienerlolaan 5, 7522 NB Enschede, The Netherlands
}

\begin{abstract}
As of $21^{\text {st }}$ century, cancer is arguably the most complex and challenging disease known to mankind and an inevitable public health concern of this millennium. Nanotechnology, suitably amalgamated with cancer research, has ushered an era of highly personalized and safer medicines which can improve cancer diagnosis and therapy. A wide variety of nanomedicines are currently under investigation, including polymeric/non-polymeric nanoparticles, dendrimers, quantum dots, carbon nanotubes, lipid- and micelle-based nanoparticles. The bases of these nanomedicines in reducing toxicity associated with cancer therapy are their ability to carry a large payload and multivalent-ligand targeting. This imparts specificity for targeting the tissues as well as bypass resistance mechanisms. The major hurdles on these future medicines are potential toxicity of nanoparticles, which imposes the need of extensive regulatory evaluation before nanomedicines could be utilized as cancer therapeutics. This review highlights nanopharmaceuticals that have been investigated in oncology for various applications (diagnosis, therapeutic delivery and theranostics). It also discusses the effects of nano-sized materials on tissues/organ functions, the possibility of overcoming multi-drug resistance by using nanomedicines and their current clinical status.
\end{abstract}

Keywords: Cancer nanomedicine, multi-drug resistance, nanotechnology, nanotoxicity, regulatory, theranostics.

\section{INTRODUCTION}

The practice of cancer therapy has changed considerably in the past decades. Curative treatments have been achieved for a number of fatal malignancies such as testicular cancer, lymphomas and leukemias. However, there are still numerous constraints associated with the use of conventional chemotherapeutic agents. Although some of the newer agents indirectly target the survival of tumor cells, viz. bevacizumab (Avastin) inhibits tumor angiogenesis [1], and ipilimumab is an immunotherapeutic antibodiy [2], the majority of them act by directly killing the cells in a more or less specific manner. Such agents are associated with doselimiting side-effects and anticancer drug resistance, since complete elimination of malignant cells is often not possible using therapeutic doses. To overcome these problems, various approaches are being developed that use nanocarriers for targeting tumor site via passive or active means $[1,2]$. According to the US Food and Drug Administration (FDA), nanotechnology product refers to products that are at least one dimension in the length scale between 1-100 nm and display functional behavior in relation to their nanosized properties [3]. Tailor-made nanomaterials can be useful for

\footnotetext{
*Address correspondence to this author at the Department of Pharmaceutics, Department of Pharmaceutical Sciences, Utrecht University, Universiteitsweg 99, 3584 CG, Utrecht, The Netherlands; Tel: +31(0) 649517651;

E-mail: S.Akhtar@uu.nl, sohailakhtermph@gmail.com
}

reducing multi-drug resistance, evading blood-brain barrier (BBB), and diagnosis and imaging of cancer [3]. Even though the research in pharmaceutical nanotechnology is in a very active stage, approved nanomedicines in the clinical practice is very low. However, it is encouraging to observe that there are many nanoformulations that are either approved, or in different phases of clinical trials [4]. The commercially available nanomedicines that are clinically employed in cancer treatment are $\operatorname{Doxil}^{\circledR} / \mathrm{Caelyx}^{\circledR}$ and Abraxan $\mathrm{e}^{\circledR}$. Doxil ${ }^{\circledR}$ is a liposomal formulation of doxorubicin, which is approved for treatment of Kaposi's sarcoma, refractory breast and ovarian cancer. Abraxane ${ }^{\circledR}$ is an albumin-based formulation of paclitaxel that has been approved for the treatment of metastatic breast cancer. Despite the progress of some nanomedicines in clinical practice, there are still issues related to their tissues/organ biodistribution, toxicity, environmental and regulatory aspects. This manuscript reviews mechanisms of action, toxicity, and regulatory aspects, recent advances, and future prospects of different nano-carriers developed as anticancer therapeutic and diagnostic agents (theranostics).

\section{TARGETING STRATEGIES AND ROLE OF NANOMEDICINE}

Tumor blood vessels possess distinctive pathophysiological characteristics that are not observed in normal blood vessels, viz. a relatively high proportion of proliferating endothelial cells, increased tortuosity, pericyte deficiency and aberrant 
basement membrane. Moreover, tumors also feature a decreased lymphatic drainage resulting in increased retention of extravasated macromolecules. This phenomenon is described as "enhanced permeation and retention (EPR) effect" [5-7], which is often proposed as the underlying mechanism for the accumulation of nanocarriers in tumors, and forms the basis of passive targeting. Alternatively, nanocarriers can accumulate in tumors by active targeting strategy, which involves binding of nanomaterials to surfaceexposed receptors on tumor cells or tumor blood vessels. Passive and active targeting will be discussed in more detail in the later section. Therefore, irregular tumor vasculature and impaired lymphatic drainage create high interstitial fluid pressure with an extremely hydrophilic environment [6], which may limit the distribution of drugs to solid tumors. Likewise, the presence of extracellular matrix of the tumor, fibrillar collagen, and necrotic non-supporting regions serve as barriers for the effective delivery of drugs [6-9]. It has been proposed that antiangiogenic agents may normalize an efficient blood flow to tumors, which will decrease the hypertensive interstitial condition, thereby improving the delivery of chemotherapeutics [10]. Drugs that have been shown to successfully normalize the tumor vasculature include anti-VEGF antibody bevacizumab [11].

\section{Passive Targeting}

Fast growing vascularization, leakiness and defective lymphatic drainage all contribute to the retention of macromolecules and nanoparticles in tumors, which is the rationale for EPR-based drug targeting. Studies with liposomes and other nanoparticles have indicated that the cut-off size of the pores in tumor vessels is as large as 200 $\mathrm{nm}-1.2 \mu \mathrm{m}$ [12-15]. In fact, it is now established that nanoparticles with a size range of 10-100 $\mathrm{nm}$ can accumulate in tumor tissue via EPR effect [12-13]. Both, the size of nanoparticles and their surface properties must be tailored appropriately to avoid phagocytosis by the RES (reticuloendothelial system). Hydrophilic surface coating of nanoparticulate systems by PEG, poloxamers, poloxamine, polysachharide and branched/block amphiphilic co-polymers have been successfully applied for this purpose [12-14].

\section{Active Targeting}

Active targeting approach is based on the interaction of a ligand-equipped nanocarrier with surface-exposed receptors on target cells, which will help in their accumulation in tumor and, more importantly, will facilitate their intracellular accumulation via receptor-mediated endocytosis [15-17]. Most cancerous cells have one or more types of overexpressed molecular targets which may serve as the site for active targeting through nanomedicine. Endocytosed particles are transported to endosomes and subsequently to lysosomes, where further processing of the particles and release of $\operatorname{drug}(\mathrm{s})$ is affected by the presence of lysosomal enzymes and low $\mathrm{pH}$ of this intracellular compartment. Active targeting mechanisms provide an alternative means to combat multi-drug resistance (MDR) because resistance inducing proteins such as P-glycoprotein (P-gp) cannot pump out nanoparticle-associated drug or drug-polymer conjugates that have entered the cell via the endocytic mechanism [15-21].

\section{Folate Receptor-Based Targeting}

Folic acid, an oxidized form of folate, is a vitamin required for one-carbon transfer reactions and is essential for the de novo biosynthesis of DNA and several nucleotide bases [22]. Folate transport across plasma membrane in normal cells is carried out either by folate carrier or by folate receptor [23]. Folate receptor is a highly selective tumor marker, which is overexpressed (100- to 300-times higher than in normal tissue) in many human cancer cells such as brain, kidney, breast and lung [24]. Therefore, folate-based targeting ligands find potential applications in the diagnosis and delivery of chemotherapeutic agents [23]. Their high receptor affinity and restricted interaction with normal tissues facilitate the delivery of therapeutic agents selectively to the target site [25-28].

\section{Monoclonal Antibody-Based Targeting}

Monoclonal antibodies (Mabs) are antibodies obtained from a single clone of a parent immune cell. These are immunoglobulins based on complex proteins, which contain mainly two regions; the antigen-binding fragment (Fab) and complement fixing fragment $(\mathrm{Fc})$, which are responsible for specific antigen binding and fixing complement for in-vivo biological response [29]. Primary tumors as well as metastatic tumors generally over-express certain antigens on their surfaces (like HER2 in breast cancer, epidermal growth factor receptor in lymphoma, etc.). Mabs specific to particular antigens provide an ideal platform for conjugated drug targeting [30]. Current research is being focused on the development of chimeric and fully humanized derivatives of such targeting Mabs to decrease their immunogenicity [31]. PLGA immuno-nanoparticles conjugated with Mabs directed to breast cancer cytokeratins interacted specifically with MCF-10A neoT [32]. Steinhauser and co-workers suggested trastuzumab-modified nanoparticles for the treatment of HER2-over-expressing breast cancer cells [33]. In 2004, Gemtuzumab-ozogamicin (Mylotarg), which is targeted to the cell-surface receptor CD33, was approved by FDA for the treatment of acute myelogenous leukemia (AML) [34]. This conjugate was however withdrawn from the market in 2010 due to fatal toxicity in phase-3 clinical trials.

Beside this, several other drug-antibody conjugates have been developed. Some of them are already approved while others are in different phases of clinical trials. From this category, Brentuximab vedotin that binds to CD30, a tumorspecific marker of the TNF-receptor superfamily, has recently been approved for the treatment of Hodgkin and systemic anaplastic large cell lymphomas [35, 36]. Additionally, Inotuzumab ozogamicin (target: CD22) and Trastuzumab emtansine (target: HER2) have shown pronounced clinical activity in phase 3 clinical trials for non-Hodgkin lymphoma, acute lymphocytic leukemia and metastatic breast cancer $[35,37]$.

\section{CD95 Targeting}

CD95 is a tumor necrosis factor (TNF) receptor that prompts cell apoptosis of peripheral T-cells upon oligomerization [38]. CD95-mediated immunological destruction of liver tissue (in hepatitis) and the CD95 death system's role in killing infected hepatocytes is well established. 
McCarron et al. reported a novel immuno-nanoparticle against colorectal tumor cells. Nanoparticles were peripherally coated with antibodies directed to CD95 and loaded with camptothecin. Effective internalization was confirmed by fluorescence visualization studies in HCT116 cell line. Similarly, they developed camptothecin nanoparticles without anti-CD95 Mab, which showed poor internalization kinetics [39].

\section{Transmembrane Tyrosine Kinase Receptor Targeting}

Huh et al. successfully worked on metallic nanoparticles tagged with trastuzumab leading to localized intratumoral accumulation in-vivo [40]. Akira et al. encapsulated metallic nanoparticles (MNPs) in anti-HER2 immunoliposomes and used these antibody-directed nanoparticles for hyperthermia therapy [41]. Similarly, gold nanoshells were developed for targeting and photothermal therapy of HER2 over-expressing ovarian cancer OVCAR3 cells. OVCAR3 cells that had internalized the metallic nanoparticles were irradiated with near infra-red (NIR) radiation leading to selective destruction of cancer cells through photothermal ablation [42]. Parallel to this theme, Day et al. developed gold-gold-sulphide nanoparticles that were used in photo-ablation therapy. These nanoparticles could be imaged via multiphoton microscopy and could induce thermal damage via hyperthermic NIR [43].

\section{Aptamer-Based Targeting}

Identification of target proteins having a clear link with human oncologic disorders offers a powerful tool for the development of relevant aptamer ligands. Aptamers, a class of macromolecules containing single-stranded RNA or DNA (ssRNA or ssDNA), can be selected from random pools, based on their antigen binding affinity [44, 45]. A group of researchers have hypothesized an automated selection process (termed as "systematic evolution of ligands") by exponential enrichment for rapid isolation of RNA ligands and aptamers [46]. Aptamers possess many favorable characteristics such as ease of chemical isolation, selective binding affinity, small physical size, and lack of immunogenicity, which make them useful as homing ligands in nanomedicine-based cancer therapy [47-50]. Furthermore, aptamers can be surface-modified with various functional groups to facilitate their conjugation with nanomaterials, which could be exploited for their selective targeting in the diagnosis and therapy of cancer [46, 48, 49]. Nanoparticles (PLGA-block-PEG copolymer) along with A10 aptamer bioconjugates have been targeted to prostate-specific membrane antigen (PSMA), which is a transmembrane protein responsible for prostate cancer [49]. In another study, a marked reduction in tumor size was observed over a period of 109 days after a single intra-tumoral injection of aptamerdecorated nanoparticles [50]. Their specific binding affinity with PSMA cells was further confirmed by in-vivo cellular imaging techniques using an aptamer conjugated to luminescent CdSe and CdTe nanocrystals, which were found to be more concentrated in prostate tumor cells. Research is being directed for the development of aptamers that can bind selectively to vascular endothelial growth factor (VEGF), a protein involved in angiogenesis. They would especially be useful in the treatment of age-related macular degeneration [51].

\section{Integrin-Based Targeting}

Integrins were originally characterized as a family of cell adhesion receptors that bind to extracellular matrix and cellsurface ligands. The role of cell-surface integrin is to transmit and detect changes from the extracellular matrix to intracellular signaling, and thus regulate tumor growth, angiogenesis, proliferation, apoptosis and metastasis [52]. Several integrins play a key role in promoting tumor angiogenesis and metastasis. Within the family, $\alpha_{v} \beta_{3}$ integrin adhesion receptor is the main marker of angiogenic blood vessels in the mammalian system, and is over-expressed on growth factor-activated endothelial cells. A synthetic peptide bearing Arg-Gly-Asp sequence specifically binds to the $\alpha_{v} \beta_{3}$ integrin and can be used to selectively target angiogenic blood vessels [53].

\section{Drug Like Peptides: Vasoactive Intestinal Peptide}

Vasoactive intestinal peptide (VIP) is a 28 -amino acid neuropeptide of the glucagon-secretin category that is distributed widely in both the central and peripheral nervous systems. VIP receptors are five-times more abundant in breast cancer cells than in normal breast cells. Additionally, VIP is synthesized locally within the eye and takes part in immunological homeostasis of the ocular microenvironment. However, its potential therapeutic applications are restricted because of its failure to cross the blood-brain barrier (BBB), rapid elimination and degradation (half-life $<1 \mathrm{~min}$ ) after i.v. administration. Therefore, various formulation-based approaches have been explored to protect its degradation and make it available in the intact form, mostly via the nose-tobrain pathway. For brain delivery, a VIP analogue was conjugated to OX26 monoclonal murine antibody and directed against the rat transferrin receptors [54]. Embedding VIP into wheat germ agglutinin-coated PEG-PLA or protamine-oligonucleotide nanoparticles enhanced their transport to the brain after intranasal administration [55]. The VIP receptor, in addition to HER-2 and estrogen receptors, is present in high density and considered as the biomarker or molecular target for breast cancer. The overexpression of VIP receptors is increasingly being used to develop new drugs for the treatment of cancer patients. Targeting PEGylated liposomes, which contain radionuclides to VIP receptors of tumor, resulted in an enhanced passive and active breast cancer inhibition in rats [56].

\section{Luteinizing Hormone-Releasing Hormone (LHRH) Targeting}

Luteinizing hormone-releasing hormone (LHRH) is another targeting moiety. The LHRH receptor is barely present on the surface of most healthy human cells, but is over-expressed in ovarian and some other cancer cells [57, 58]. Dharap et al. recently developed the LHRH-PEGcamptothecin targeted anticancer drug delivery system, wherein LHRH targets the corresponding receptors in cancer cells, PEG prolongs the blood circulation time, and camptothecin functions as the anticancer drug [58]. The targeted conjugate exhibited significantly higher cytotoxicity against cancer cells than the non-targeted PEG-camptothecin conjugate or the free drug in vivo, indicating the validity of actively targeted nanoparticles for anticancer therapy. The 
list of various targeting ligands and their respective targets are given in Table $\mathbf{1}$.

\section{CLASSIFICATION OF NANOCARRIERS IN ONCOLOGY}

Advancement and growing interest in nanotechnologybased drug delivery systems and imaging agents have dramatically increased their market potential. The market of nanopharmaceuticals is growing by $17 \%$ and expected to have a $\$ 53$ billion market in 2014. Hence, a steady succession of nanomedicines is anticipated to seek regulatory approvals and subsequent access to human use. Nanomedicines have several features that make them especially adept at carrying anticancer compounds to tumors. First, they are large enough to avoid rapid elimination through the kidney, yet they are small enough that they may penetrate the leaky vasculature of the tumor tissues and get trapped because of the EPR effect; nanoparticles only show this EPR effect in tumors or inflamed tissues that also have a leaky vasculature, while they avoid normal tissues to a large extent since they cannot penetrate the intact endothelial barrier. Second, nanomedicines can enter a cell by endocytosis very efficiently especially when decorated with targeting ligands. Furthermore, after intracellular accumulation, nanocarriers protect the particle's payload from being expelled by cellular pumps that otherwise are responsible for drug resistance. Nanoparticles are useful carriers especially for drugs that operate intracellularly such as interference RNA. Another attractive feature of nanoparticulate systems is that they can incorporate multiple drugs, making combination therapy possible on a single platform. On the basis of application in oncology, nanopharmaceuticals may be classified as therapeutics, diagnostics or theranostics (i.e. combination of both). The developed nanocarriers for medicines are illustrated in Fig. (1). Diverse classes of nanomedicines have been developed till now and they have their own advantages and disadvantage as drug carriers (Table 2).

\section{Liposomes}

Liposomes are a family of microscopic, concentric lamellar structures enclosing an aqueous volume by a membranous lipid bilayer. They are formed by blending natural or synthetic phospholipids, cholesterol and tocopheryl acetate, and their subsequent hydration in the aqueous media. Liposomes have been studied and evaluated extensively for the spatial and temporal delivery of anticancer agents. First liposomal product approved by FDA is Doxil ${ }^{\circledR}$ in 1995 for the treatment of Kaposi's sarcoma, refractory breast and ovarian cancer. Liposomes qualify as suitable candidates for delivering drugs in oncological disorders owing to their straightforward formulation methodology, as well as their versatility in entrapping both hydrophilic and lipophilic drugs [59-61]. PEGylated or stealth liposomes (long circulating) exhibit remarkable inhibition of the rapid uptake by the RES cells, leading to an improved extravasation profile and enhanced intratumoral localization. Conjugation of a targeting ligand to liposomes can take the tumor targeting approach to a higher level. A study conducted pertaining to the uptake of folate-PEG-

Table 1. Different targeting ligands, specific targets and their application in drug targeting in different cancers.

\begin{tabular}{|c|c|c|c|c|}
\hline Targeting Ligands & Specific Targets & Location & Targeting Application in Oncology & References \\
\hline NGR peptide & Aminopeptidase $\mathrm{N}$ & Cell surface & Vasculature in solid tumors & {$[150]$} \\
\hline$A b \& A b$-derived peptides & Aminopeptidase $\mathrm{P}$ & Caveoli & Lung cancer & {$[151]$} \\
\hline $\begin{array}{l}\text { Antibody (Rituxan, } \\
\text { Zevalin) }\end{array}$ & $\begin{array}{l}\text { B-lymphocyte antigen } \\
\text { CD20 }\end{array}$ & Cell membrane surface & B cell lymphomas & {$[152,153]$} \\
\hline$A b($ Erbitux $)$ aptamers & EGF receptor (ErbB1) & Cell membrane surface \& lipid rafts & Metastatic colorectal cancer & [154] \\
\hline$A b$, Ab-derived peptide & Endoglin & Cell membrane surface and caveoli & Vasculature in solid tumors & [155] \\
\hline $\begin{array}{l}\text { Peptides, } A b, A b \text {-derived } \\
\text { peptides }\end{array}$ & ICAM-1 & Cell membrane surface & Vasculature in solid tumors & {$[156]$} \\
\hline Ab (Avastin), peptides & VEGF receptor & Cell membrane surface & Vasculature in solid tumors & {$[157]$} \\
\hline$A b \& A b$-derived peptides & PECAM-1 & Cell membrane surface & lymphoid cancers & {$[158]$} \\
\hline Ab aptamers & MUC1 & Cell membrane surface & Breast \& bladder cancer & [159] \\
\hline Albumin \& Ab & gp60 & Caveoli and Cell membrane surface & $\begin{array}{l}\text { Vascular targeting in malignant } \\
\text { liver cancer }\end{array}$ & {$[160]$} \\
\hline $\begin{array}{l}\text { Trastuzumab (Herceptin), } \\
\text { pertuzumab Ab, tyrosine } \\
\text { kinase inhibitors }\end{array}$ & $\begin{array}{l}\text { EGF }(\text { ErbB) receptor } \\
(\text { ErbB1) and EphA2 } \\
\text { receptor }\end{array}$ & $\begin{array}{l}\text { Cell membrane surface and lipid } \\
\text { rafts }\end{array}$ & $\begin{array}{l}\text { Breast, prostate cancer, and } \\
\text { Metastatic colorectal cancer }\end{array}$ & {$[161]$} \\
\hline $\begin{array}{l}\text { Ab, Ab-derived peptides, } \\
\text { aptamers }\end{array}$ & $\begin{array}{l}\text { insulin-like growth } \\
\text { factor receptor (IGF-1R) }\end{array}$ & Caveoli and Cell membrane surface & Lungs, pancreas and breast cancer & {$[162,163]$} \\
\hline
\end{tabular}




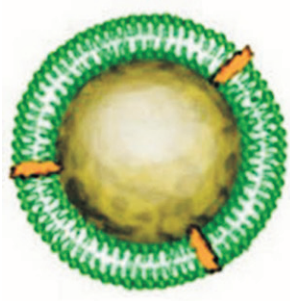

I.A

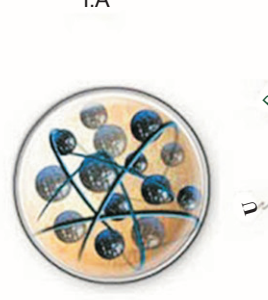

V
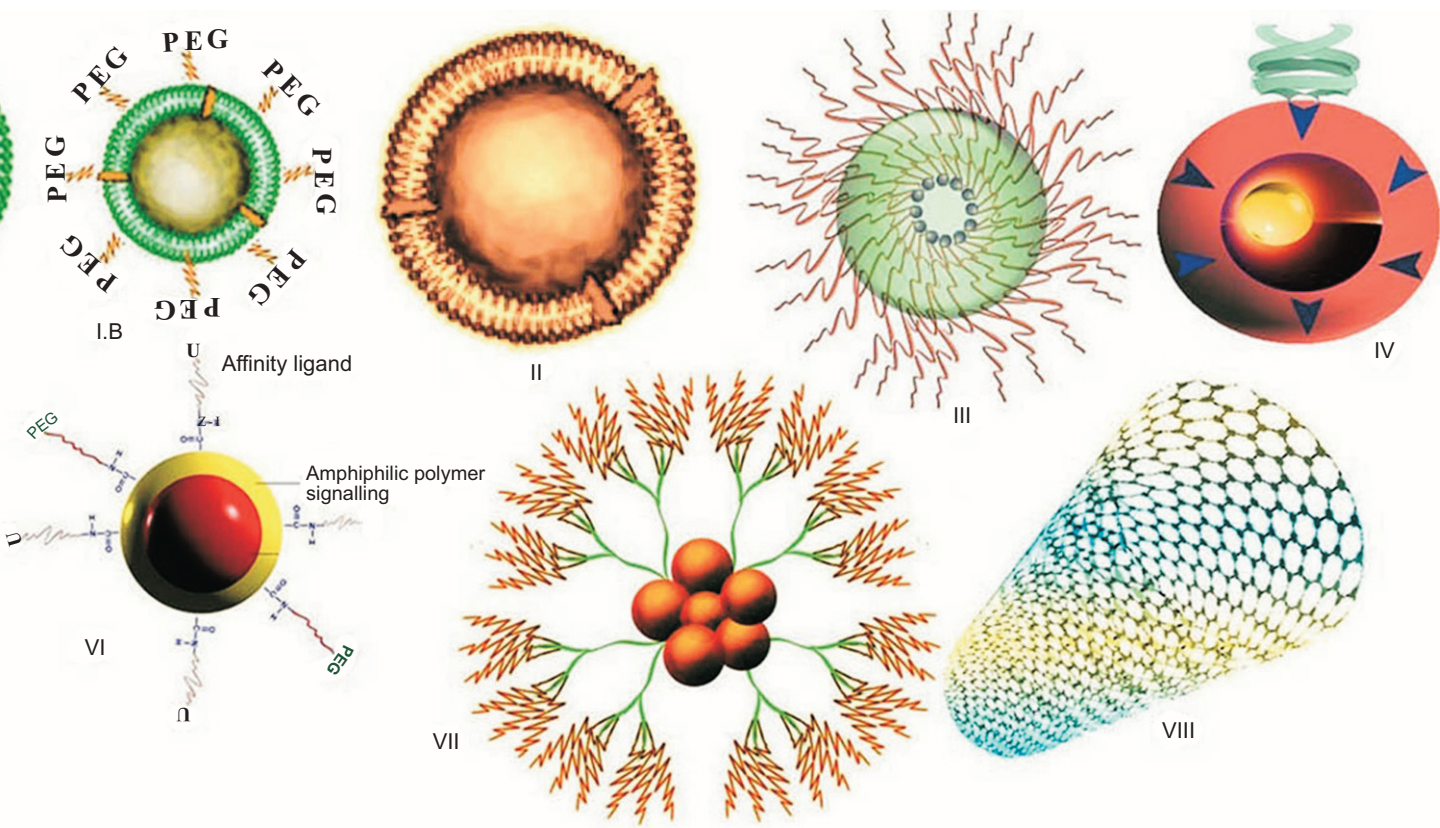

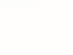
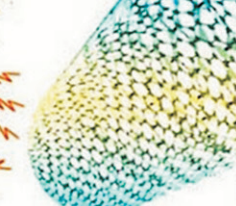

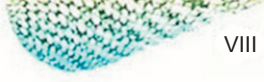

Fig. (1). Diagrammatic illustration of different nanomedicines used in oncology.

liposomal doxorubicin by KB cells (a cell line derived from human carcinoma of nasopharynx) showed 45-fold higher uptake of folate-targeted liposomes than of liposomal doxorubicin and 1.6-fold higher uptake versus free doxorubicin, while cytotoxicity was 86 and 2.7 times higher, respectively [62]. Opsonisation of plasma proteins to nanocarriers greatly enhances their clearance. To diminish this, albumin was conjugated to PEGylated doxorubicin liposomes [63]. The disposition of this type of nanoparticulate doxorubicin to the heart was significantly smaller than that of free drug, and on the other hand tumor accumulation of albumin-conjugated PEGylated liposomes was higher than the PEGylated liposomes. Liposomes can also be used to overcome the specific resistance mechanisms such as P-gp mediated drug efflux, and targeting drugs to tumor tissue and cells, leading to enhanced bioavailability at the site of action to the resistant tumors safely and effectively [64]. Currently, liposomal anthracyclines have achieved clinical use in cancer treatment by eliciting enhanced encapsulation of drug in a stable, non-reactive carrier, providing potential benefits in case of resistant tumors.

\section{Niosomes}

Nonionic surfactant-based vesicles (NSVs) are now one of the most widely studied alternatives to liposomes, resulting from the self-assembly of hydrated surfactants monomers. Surfactants can be employed as useful surrogates to phospholipids in the fabrication of vesicular systems [65, 66], and have some advantages over liposomes like avoidance of superfluous use of phospholipid (vulnerable to oxidative degradation) thereby boosting formulation stability, and drastic reduction in production cost. The rationale behind using niosomes in anticancer therapy is to prolong the circulation of entrapped drug, altering its organ distribution and metabolic stability, as well as to reduce drug-induced toxic effects to extra-tumorous tissues. Like liposome, PEGylation and surface modification for enhanced tumor targeting is also possible. Lately, it has been shown that efficient tumor targeting of hydroxycamptothecinloaded pegylated niosomes is possible when modified with transferrin [67].

\section{Polymeric Micelles}

The promising potential of polymeric micelles (PMs) as effective drug delivery carriers in anticancer therapy has been a topic of discussion since decades. The major breakthrough was witnessed in the early 1990s by Kataoka's group, who developed doxorubicin-conjugated block copolymer micelles [68, 69]. Since then, a large number of modified pendant polymeric micelles have been used for the delivery of chemotherapeutic agents in pre-clinical and clinical studies. A polymeric micelle essentially consists of an inner hydrophobic core (which is the part of block copolymer) and encapsulates a hydrophobic/poorly-water soluble drug, while the outer shell or the corona is composed of the hydrophilic part of the block copolymer. Some inherent properties of PMs which make them an obvious choice for carriers of anticancer drugs are: (1) size in nano range; (2) stability in plasma; (3) in vivo longevity owing to hydrophilic corona as observed in PEGylated (stealth) liposomes; and (4) EPR effect by virtue of the pathological characteristics of the tumor cells, is observed allowing passive targeting to the tumor cells [70]. The corona serves the dual purpose of stabilizing the PMs against recognition by RES cells and targeting the drugs by attaching specific ligands recognizing the tumor sites. Drug release can be coordinated and regulated by appropriate application of heat or ultrasound, or other external suitable stimuli. Thus, it can be conveniently accepted that PMs have the potential of active as well as passive targeting to the tumor tissues. 
Table 2. Common preparation methods, advantages and limitations of different nanocarriers in anticancer drug delivery.

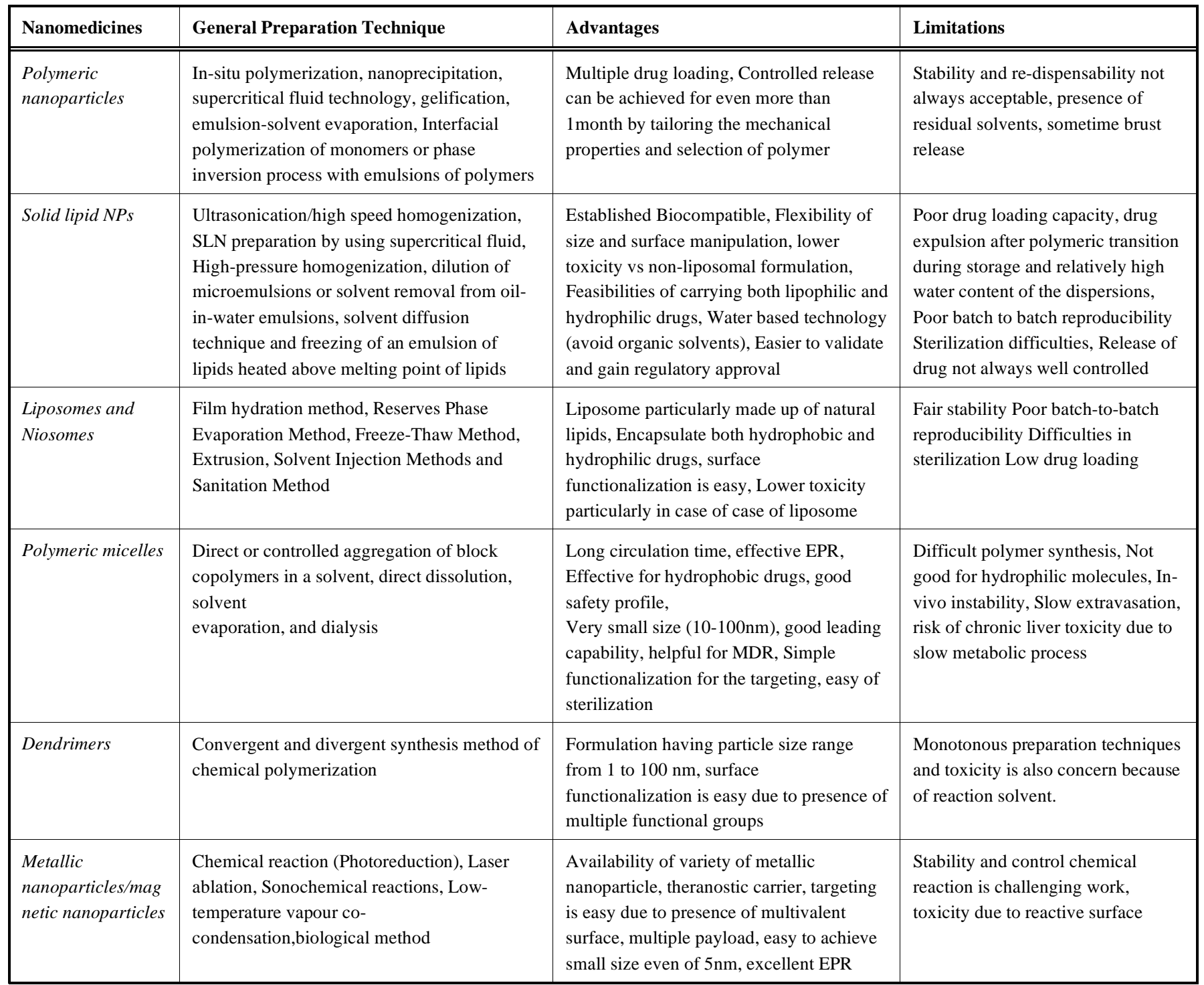

Tumor angiogenesis and tumor cell targeting of PMs is a prospective application [71].

\section{Polymeric Nanoparticles}

Encapsulation, dissolution, entrapment of drug in nanosized particles or their attachment to a polymeric matrix gives rise to polymeric nanoparticles (NPs). A plethora of well-studied biodegradable polymers like PLA, PLGA, Poly$\varepsilon$-caprolactone, etc., are used to fabricate polymeric NPs, maximizing tissue compatibility and minimizing toxicity due to their biocompatibility and biodegradability. Alternatively, synthetic polymeric agents can also be used to formulate NPs and the accompanied advantages include increased biological half-life, reduced uptake by the RES cells and improved targeting to tumor cells. Mu and Feng synthesized PLGA NPs containing the drug Paclitaxel (PTX) (Taxol ${ }^{\circledR}$ ) for solubility enhancement [72]. Gryparis and co-workers observed the in vitro anticancer activity of cisplatin-loaded PLGA-mPEG NPs on human prostate cancer LNCaP cells. It was found that as the PLGA/PEG ratio in PLGA-mPEG copolymer increased, the cytotoxicity also increased. This effect was observed primarily due to increased uptake by cells with the increasing ratio. Furthermore, it was also concluded that the in vitro activity of cisplatin was comparable to free cisplatin [73]. Li et al. prepared multifunctional pluronic/polyethylenimine NPs conjugated with folic acid (as folate) to their surface to improve targeting to tumor cells. They concluded that the surfacemodified PTX nanoparticles showed sustained release profile in contrast to PTX solution [74]. Additionally, the in vitro anticancer activity was also enhanced considerably as compared to free drug, and folate conjugated nanoparticles demonstrated excellent cytotoxic action. In a similar experiment conducted by Mo and Lim, PTX-loaded PLGA NPs were conjugated with wheat-germ agglutinin (WIT-NP) which showed superior cytotoxicity towards A549 and H1299 cell lines as compared to conventional PTX formulations (as measured by IC-50 doses). This superiority was attributed to a more efficient and complete intracellular 
PTX accumulation via WGA-receptor mediated endocytosis and IPM-facilitated intracellular drug release. WIT-NP cytotoxicity can be ascribed to PTX-induced tumor cell apoptosis and cell cycle arrest at $\mathrm{G}_{2} / \mathrm{M}$-phase [75].

\section{Solid Lipid Nanoparticles (SLN)}

SLNs offer an attractive and efficient means of drug delivery, particularly for hydrophobic, poorly water soluble drugs. They combine the advantages offered by liposomes, NPs and fatty emulsions. SLNs are comparatively stable colloidal carrier systems in which the drug is entrapped in a lipid core, and manufactured by high-pressure homogenization or microemulsification technique [76]. Significant advantages presented by SLNs over polymeric systems are their low toxicity due to lipid biodegradability, and small size which helps to bypass the RES.

\section{Inorganic Nanoparticles}

The synthesis of inorganic NPs is an active area of application research in nanotechnology. Some common metals of utility in anticancer drug delivery include gold $(\mathrm{Au})$, copper $(\mathrm{Cu})$, and silver $(\mathrm{Ag})$, and other non-metallic inorganic carriers, such as silica. Among these, gold NPs have emerged as superior carriers following their excellent optical and photoelectric properties, inertness and nontoxicity, higher stability, ease of preparation, scope for bioconjugation and bio-modification with thiol, disulfides and amino groups. Their dispersibility can be augmented by conjugation with thiolated-PEG [77]. Important areas of gold NPs applications are their use as contrasting agents in diagnosis, and in photothermal cancer therapy. In recent years, gold NPs are most extensively evaluated in oncology as compared to the other metallic NPs. Gold NPs have unique properties that make them potential candidates in therapeutic oncology [78-81]. Gold nanomaterials have optical properties with high absorption efficiency particularly in the IR region that can easily be enhanced by changing the shape and surface area at the nano scale [81]. Gold nanomaterials in particular shapes like nano-rods, nano-stars, nano-cages and nano-shells show excellent localized surface plasmon resonant properties which particularly favor their applicability in oncology. The highly tunable and multivalent surface of gold NPs favor high payload by covalent or non-covalent conjugation [82, 83]. Furthermore, it is possible to functionalize the gold NPs for active targeting with targeted ligands. For example, PEGylated gold NPs have been conjugated with human transferrin (Tf) by amine-carboxylate reaction that showed significantly improved uptake of particles in cancer cells after i.v. administration to mice bearing Neuro2A tumors [84].

Shen and co-workers demonstrated effects of functionalized gold NPs on the binding of dacarbazine to DNA bases. They illustrated the apparent enhancement of the electrochemical response of dacarbazine revealing the facilitation of specific interactions between the drug and DNA bases [85]. Cherukuri et al. presented an informative review on the emerging role of NPs especially gold in the hyperthermic treatment of cancer. Metallic NPs induce hyperthermic cytotoxicity when exposed to near-infrared radiation or radiofrequency fields [86]. Recently, a couple of reviews presented by Akhter et al. [87] and Ahmad et al. [88] elaborated the properties and applications of metallic NPs in oncology.

\section{Magnetic Nanoparticles}

The basis behind the formulation of magnetic nanoparticles (NPs) is the fact that the drug is either encapsulated into magnetic micro-/nanosphere or conjugated onto them, or implanted as a magnetically-active disc. The drug release to the blood stream can be controlled utilizing a powerful magnetic field in the target tumor area. Magnetic materials receive their magnetic responsiveness to a magnetic field from materials like magnetite, iron, nickel, cobalt, neodymium-iron-boron, and samarium-cobalt. Ferrofluids are liquids which become strongly magnetized in the presence of a magnetic field. They are colloidal liquids of nanoscale ferromagnetic particles suspended in a carrier fluid (organic/aqueous). Iron oxide NPs is the most commonly used due to its biodegradable nature, biocompatibility, superparamagnetic effects and ability to serve as a contrast agent in MRI. Once compartmentalized within the lysosomes of RES cells, they disintegrate to ferritin and/or haemosiderin (antiferromagnetic forms of iron) [89]. A water-dispersible oleic acid (OA)-pluronic-coated iron oxide magnetic NP formulation was developed by Jain et al. and subsequently loaded with high doses of water-insoluble anticancer agents. This formulation was used as a universal drug carrier system for systemic administration of water-insoluble drugs, and simultaneously permitting magnetic targeting and/or imaging [90]. Yallapu and co-workers have developed a multilayer approach for water-dispersible superparamagnetic iron oxide nanoparticles (SPIONS) for hyperthermia, MRI and drug delivery applications. Iron salts, in the presence of ammonia, were precipitated to obtain iron oxide core NPs and coated with $\beta$-cyclodextrin and pluronic polymer. Consequently, the formulation was highly water dispersible, enabling entrapment of anticancer drugs in $\beta$-cyclodextrin and pluronic polymer coatings for sustained drug release and showed superior hyperthermia effects with time under alternating magnetic fields as compared to pure magnetic nanoparticles and $\beta$ cyclodextrin coated NPs [91]. In yet another study conducted by Maeng et al., multifunctional doxorubicin-loaded SPIONS for chemotherapy and MRI in liver cancer were developed. Polymeric NPs composed of poly(ethylene oxide)-trimellitic anhydride chloride-folate, doxorubicin, superparamagnetic iron oxide and folate, and exhibited superior anticancer activity by targeting folate receptor (FR)-expressing tumors, thus enhancing the bioavailability and efficacy of the drug [92].

\section{Dendrimers}

Dendrimers form an important connecting link between molecular chemistry and polymer science [92]. They are highly branched, globular, monodisperse, nanoscaled, and uniformly distributed three-dimensional polymeric macromolecules consisting of three distinct domains: (a) a central core containing a single atom/atomic group with at least two identical chemical functions, (b) branches emanating from the core, comprising of repeating units organized in geometric progression resulting in a series of 
radially concentric layers called "generations", and (c) exteriorly located terminal functional groups. Since they possess both hydrophobic and hydrophilic areas, drug molecules can be loaded depending upon their solubility characteristics. They serve as an ideal targeting and imaging agents due to their highly asymmetric shape, multiple branching and multivalent tree-like structures. Among different dendritic polymers, polyamidoamine (PAMAM) dendrimers are the most widely used for chemotherapeutics. In the recent past, multifunctional PAMAM dendrimers with an imaging agent (fluorescein isothiocyanate) conjugated with biotin and folic acid as targeting ligands, and taxol as therapeutic agent have been elucidated for parallel use in diagnosis and therapy. Conjugation of partially-acetylated PAMAM dendrimers with imaging modalities might be used for cancer therapy and diagnosis. Enhanced drug loading and extended delivery of 5-fluorouracil was observed with pegylated PAMAM dendrimers, with few blood dyscrasias due to restricted uptake of drug through RES [93]. Gardikis et al. developed a liposomal-locked indendrimer (LLD) formed by dipalmitoylphosphatidylcholinedipalmitoylphosphatidylglycerol (DPPC-DPPG) lipids and poly(amido amine) incorporating the drug doxorubicin. The study showed that phase separation between DPPC-DPPG lipids and dendrimer promote the stability of liposomal membrane and co-operativity of the relevant gel to liquid crystal transitions, which is augmented in the presence of dendrimers and drug [94].

\section{Carbon Nanotubes (CNTs)}

Over the last several years, CNTs have been extensively explored in almost every single cancer treatment modality, including drug delivery, lymphatic targeted chemotherapy, thermal therapy, photodynamic therapy and gene therapy. CNTs were first discovered by Iijima in 1991 [95]. They belong to the family of fullerenes, i.e. the third major allotropic form of carbon after graphite and diamond [96]. They are structurally thin sheets of benzene ring carbons rolled up uniformly to form a smooth, seamless rod-like tubular structure. CNTs can be single-walled (SWNT), which essentially consist of a layer of cylinder graphene, or multi-walled (MWNT) containing several concentric graphene sheets [96]. Some important techniques to produce CNTs are laser ablation, electric arc discharge, and thermal or plasma-enhanced chemical vapor deposition (CVD) [97, 98]. Liu et al. synthesized a series of amphiphilic polymers by anchoring PEG of different lengths at various densities on poly(maleic anhydride-alt-1-octadiene) [PMHC 18$]$. PEG$\mathrm{PMHC}_{18}$-coated SWNTs in mice after i.v. injection showed ultra-long elimination half-life and significantly higher tumor uptake [98]. Chen et al. demonstrated that a higher epirubicin loading can be achieved by utilizing carboxylated CNTs (cMWNT) [99]. The loading process was mainly attributed to $\pi-\pi$ stacking between epirubicin and graphene surface of CNTs. Carboxylic acid group also facilitated functionalization with the targeting group that PEGylated MWNTs penetrated mammalian cells without damaging the plasma membrane and selectively accumulated in MDRcancer cells as efficiently as in sensitive cancer cells [99]. These intracellular translocations of PEGylated MWNTs were visualized in MDR-Hep G2-DR and sensitive Hep G2 cells, as observed by fluorescence and transmission electron microscopy. This study, thus gives the strong evidence regarding development of PEGylated MWNTs as an efficient drug carriers to conjugate drugs for overcoming MDR in cancer chemotherapy [99].

\section{Quantum Dots (QDs)}

Semiconductor QDs are nanoparticles $(2-100 \mathrm{~nm})$ that are considered as the potential candidate in traceable drug delivery because of their size-tunable absorption bands and emission color [100]. Additionally, photoluminescence of QDs is outstandingly bright and stable, making them suitable alternatives for biomedical imaging and therapeutic interventions [101]. Semiconductors from groups II-IV or III-V of the periodic table are employed, for example, indium arsenide, cadmium telluride, and cadmium selenide. Various advantages of QDs over ionizing radiations, chemotherapy and radiation therapy are: (a) high quantum yield; (b) resistance to chemical modification; (c) intrinsic fluorescence emission spectra; and (d) adjustable optical properties by regulation of size and composition. Photosensitizing QDs produce radicals upon absorption of visible light. This approach is limited for superficial tumors. Another major drawback to the use of QDs is the poor availability of photostable NIR fluorophores and photosensitizing drugs [100]. A QD-aptamer-doxorubicin conjugate functionalizing the surface of fluorescent QDs with A-10 RNA aptamer was developed by Bagalkot et al. These QDs were able to differentially uptake and image prostate cancer expressing prostate-specific membrane antigen [102]. Gao et al. developed multifunctional QD probes for simultaneous tumor targeting and imaging. Early diagnosis and individual tailorized treatment of oral cancers could be achieved by developing NIR QD conjugated with cell penetrating peptide and labelling oral squamous carcinoma cells with QD conjugates [103]. Li et al. utilized PAMAM dendrimers to modify QDs, thereby enhancing their water solubility. These dendrimer-modified QDs were conjugated with DNA aptamers specifically targeted to U251 human glioblastoma [104]. Chen et al. investigated the potential of QDs for quantitative estimation of HER2 as a micropathologic indicator of tumor size. Usage of QDs has led to a better revelation of breast cancer heterogeneity, which can, in turn be useful in formulating a more personalized and targeted therapy for breast cancer [105].

\section{RECENT ADVANCEMENTS AND FUTURE TRENDS}

\section{Attenuation of MDR (Multi-Drug Resistance)}

Resistance against drugs remains the major challenge in oncology. Drug resistance can be of non-cellular and cellular origin. Poorly vascularized tumor cells/tissues or physiological barriers are considered as the cause of noncellular drug resistance that significantly diminishes drug access to the cancerous sites. Cellular drug resistance can be due to over-expression of the drug transport pump (for example P-gp efflux transporter), drug-resistance proteins, enhancement of the DNA repair capacity and reduction of the apoptosis regulation [106]. Amongst the aforementioned mechanisms, the role of P-gp is most extensively studied. P$\mathrm{gp}$ is a $170-\mathrm{kDa}$ transmembrane glycoprotein that functions 
as an efflux system to remove xenobiotics from inner cell environment. Various P-gp inhibitors have been discovered to overcome drug resistance (e.g. cyclosporin $\mathrm{A}$, ramipril and cuminaldehyde) and among them, some of the P-gp inhibitors have shown the restoration of cancerous cell sensitivity to cytotoxic agents [106].

Alternative strategies against MDR are the development of the novel concept of nanotechnology-based drug delivery systems, which selectively target the tumor-site (cellular or tissue targeting) through selective endocytosis or passive diffusion leading to by-pass the P-gp efflux [6], for example, doxorubicin-loaded poly-(alkyl cyanoacrylate) NPs [107], metallic doxorubicin-loaded particles, PACA NPs [108] and nanoparticulate conjugate of 20 (S)-camptothecin [109]. Schluep et al. have shown the ability of such particles to overcome drug resistance [109]. In clinical studies, liposome-loaded doxorubicin was able to overcome drug resistance in AIDS-related Kaposi's sarcoma [110]. Furthermore, NPs such as polymeric micelles and polymeric conjugates as a drug delivery carrier showed promising results in patient who had previously failed to chemotherapy [110-112]. Ligand-based strategies, particularly receptor targeting, have also been applied to overcome MDR since they are able to interact with the receptor and internalized through receptor-mediated endocytosis. For example folatetargeted DOX-nanoparticles and transferring-conjugated paclitaxel NPs exhibited greater cytotoxicity than their free counterpart in MDR model [10].

\section{Nanotechnology in Cancer Theranostics}

Diagnosis and therapy combined in one system is the current advanced biomedical tool referred to as theranostics [87]. The primary goal of theranostics is to selectively target the disease confined to tissue/cell in order to increase diagnostic and therapeutic selectivity that makes the treatment shorter, safer, effective and inexpensive. Biocompatible/biodegradable nanocarriers are currently under development in oncological theranostics that would enable precise diagnosis and therapy. Lukianova-Hleb et al. have studied the light-based generation and detection of plasmonic gold NPs in living cells, with focus on tailoring the plasmonic NP properties in one cell and evaluating the multifunctionality of the nanoparticle [113]. Recently, numerous published reports discussed the design, physiochemical characteristics and applications of magnetic nanoparticles. These NPs can act both an imaging agent (diagnosis) and a drug carrier (therapy) [114]. Shim et al. coated RNA-encapsulated polyplexes, covalently bonded with gold nanoparticle through an acid labile linkage to explore theranostic use (optical imaging and gene silencing) [115]. The different possible characteristics like imaging property, drug carrying and targeting capacity with long circulating behavior (shown with PEG) are given in Fig. (2).

The multifunctionality associated with NPs includes imaging (single or dual modality), therapy (single or mutiple drugs) and targeting (uni- or multi-liganded). Although there are certain unanswered questions and challenges remaining for the establishment of NPs in clinical applications, extensive clinical data are needed, with progressive and clinical-centric efforts to overcome these queries and obstructions that will certainly lead to rational design of nanoparticles, possessing improved selectivity and efficacy. Current knowledge regarding the safety of NPs is in its infancy. The pharmacokinetic parameters and their outcome need a comprehensive exploration and generation of databases for health-risk particularly associated with vital organs need to be created. In the next few years, many applications of nanotechnology will be put to clinical practice. Table 3 summarizes the selected examples of nanomedicines which are approved by the FDA or are in some phase of clinical trial for cancer therapy.

\section{TOXICITY ISSUES}

Apart from immense importance of nanomaterials in cancer imaging and therapy, its toxic effects are also a major concern especially after chronic administration. Different polymers have different toxicities, like complement activation, carcinogenicity, teratogenicity, and immunogenicity [116, 117]. Thus choosing safe polymers for the design of NPs is itself a major hurdle. Careful evaluation of

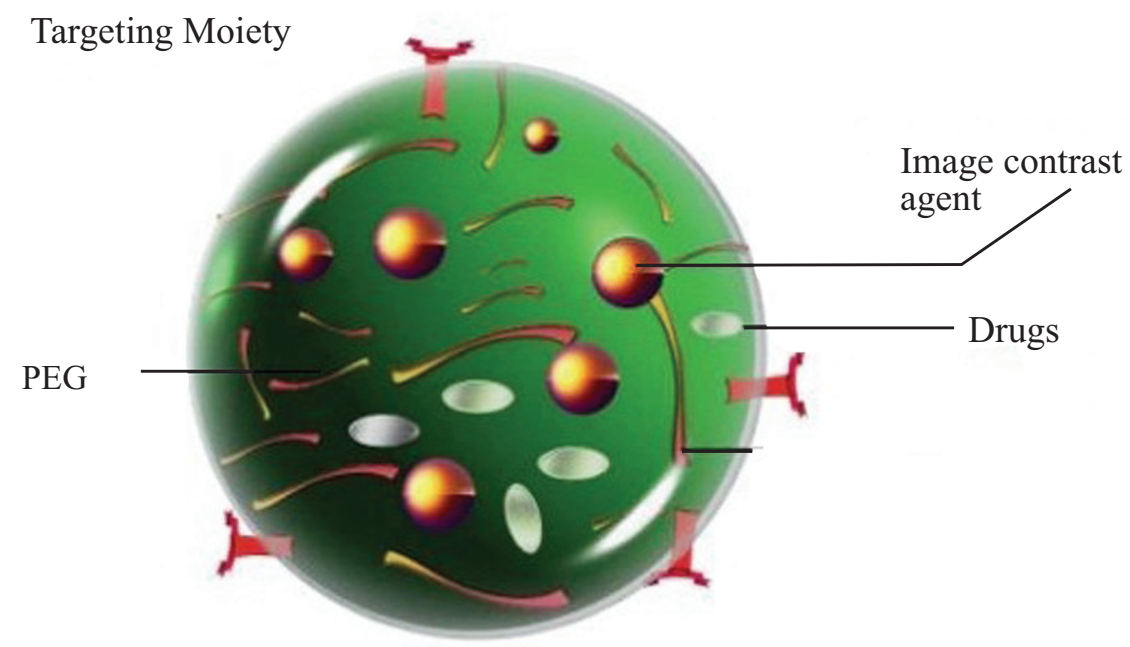

Fig. (2). Illustrative image defining the different characteristics of multifunctional nanomedicine such as imaging property, drug carrying and targeting capacity with long circulating behavior. 
Table. 3. Nanomedicine as cancer therapeutics/imaging agents under different stages of development.

\begin{tabular}{|c|c|c|c|c|}
\hline NANOMEDICINES & DRUG & APPLICATION & STATUS & REFERENCE/COMPANY \\
\hline \multirow{7}{*}{ LIPOSOMES } & CPX-1 (Liposomal irinotecan) & Colorectal cancer & Phase II & Celator Pharmaceuticals \\
\hline & INGN-401 & Metastatic lung cancer & phase I & Introgen Therapeutics Inc, USA \\
\hline & SPI-77(stealth liposome cisplatin) & Lung cancer & Phase III & ALZA pharmaceuticals, USA \\
\hline & Daunorubicin citrate & Kaposi's sarcoma & FDA approved & Gilead Sciences, Inc.USA \\
\hline & Doxorubicin & Ovarian cancer & FDA approved & ALZA pharmaceuticals, USA \\
\hline & $\begin{array}{l}\text { PEGylated liposome/doxorubicin } \\
\text { hydrochloride }\end{array}$ & Ovarian cancer & " & Ortho Biotech \\
\hline & OSI-211 (Liposomal lurtotecan) & Various cancer & Phase II & OSI Pharmaceuticals \\
\hline \multirow{2}{*}{$\begin{array}{l}\text { POLYMERIC } \\
\text { MICELLES }\end{array}$} & MRX-952 & Anticancer & Preclinial & ImaRx Therapeutics, USA \\
\hline & Carmustine & Glioblastoma multiforme & FDA approved & Guilford Pharm.Inc. USA \\
\hline $\begin{array}{l}\text { SOLID-LIPID } \\
\text { NANOPARTICLES }\end{array}$ & Paclitaxel-taxol & Mammary cancer (metastatic) & FDA approved & $\begin{array}{l}\text { American Pharm.Partner/Amer. } \\
\text { BioScience, USA }\end{array}$ \\
\hline \multirow{2}{*}{$\begin{array}{l}\text { POLYMERIC } \\
\text { NANOPARTICLES }\end{array}$} & $\begin{array}{l}\text { Copolymer of N-(2-hydroxypropyl) } \\
\text { metacrylamide/camptothecin }\end{array}$ & Various cancer & Phase I & Pharmacia, USA \\
\hline & $\begin{array}{l}\text { NK-105 (PEG-polyaspartate) } \\
\text { nanoparticle of cisplatin }\end{array}$ & Various cancer & Phase II & Nippon Kayaku Co. Ltd. \\
\hline $\begin{array}{l}\text { ALBUMIN } \\
\text { NANOPARTICLES }\end{array}$ & Albumin bond nanoparticle (Abraxane) & Mammary cancer (metastatic) & FDA approved & $\begin{array}{l}\text { American Pharm.Partner/ } \\
\text { Amer.BioScience, USA }\end{array}$ \\
\hline $\begin{array}{l}\text { CYCLODEXTRIN } \\
\text { NANOPARTICLES }\end{array}$ & Cyclosert-camptothecin & Metastatic solid tumors & IND filed & Insert Therapeutics, USA \\
\hline \multirow{2}{*}{$\begin{array}{l}\text { GOLD } \\
\text { NANOPARTICLES }\end{array}$} & Verigene & Diagnostics & Market & Nanosphere, USA \\
\hline & Aurimune (Colloidal gold/TNF) & Solid tumors & Phase II & CytImmune Science \\
\hline $\begin{array}{l}\text { SILICA } \\
\text { NANOPARTICLES }\end{array}$ & $\begin{array}{l}\text { AuroLase (Gold coated silica } \\
\text { nanoparticles) }\end{array}$ & Head and neck cancer & Phase I & Nanospectra bioscience \\
\hline
\end{tabular}

the potential toxicity of residual solvents, polymers and the developed particles is critically important. Presently, nontoxic and biodegradable ingredients are used to design NPs due to which carrier-associated toxicities tend to be mild. However, NPs accumulates in the liver, spleen, and bone marrow leading to increased toxicities to these organs. Many studies have identified liver as the primary organ responsible for reticuloendothelial capture of NPs, often due to phagocytosis by Kupffer cells. Hepatotoxicity has been observed in mice treated orally with nano-zinc particles
[118]. Similarly, i.v. administration of cationic PAMAM dendrimers to mice has been observed to cause liver injury [119]. There are also safety concerns with particular NPs that are capable of crossing the BBB. For example clinical trial of an HPMA-conjugated paclitaxel had been terminated due to neurotoxicity [120]. Among the nanomedicines, metallic nano-carriers have been extensively evaluated for their toxicity and interaction with biological systems [121]. Depending on the nature and type of metallic nanoparticles [MNPs], different grades of toxicity have been reported at 
organ, tissue, cellular and sub-cellular level due to their physiochemical properties (viz. size, shape, electrical charge on the surface, chemical composition, surface structure (surface reactivity, surface group, inorganic or organic coatings), solubility and aggregation behavior) [122-124]. The mechanisms of toxicity induced by MNPs are a combination of different events such as direct destruction of cellular component like DNA, RNA and cellular proteins due to free radical generation. Moreover, increased oxidative stress plays a key role as well [125]. Recently, it was found that 'naked' CdTe quantum dots cause damage to lipid membranes of mitochondria and nuclear structures [125]. Destruction of plasma membrane by metallic NPs was supported by the work of Sayes et al. on Cobalt $\left({ }^{60} \mathrm{Co}\right) \mathrm{NPs}$ [126]. Metallic NPs influence the reproductive organs as it was found that particles may reduce spermatogonial cell proliferation [127-130]. Free radical generation and induction of inflammatory mediators is considered pivotal for such effects [131]. Apart from the male reproductive organ, Browning et al. reported the effect of metallic NPs over female reproductive system in animal experiments [132]. They confirmed that gold NPs can diffuse into the embryo and lead to teratogenic deformities [133]. Increased surface activity due to reduction in particle size (increase in surface area:volume ratio) influences the interaction of metallic NPs to the biological system [87]. The correlation between the size and toxicity is corroborated by the report of De and co-workers that illustrated that colloidal gold NPs with small size $(10-50 \mathrm{~nm})$ cause more toxicity in comparison to the larger particles (100-200 nm) [134]. Moreover, Chen et al. studied the oral toxicity of copper NPs and found that their $\mathrm{LD}_{50}$ increased sharply with the decrease in particle size [135]. In another report, it was demonstrated that gold NPs with the size ranging from 2.8 to $38 \mathrm{~nm}$ were more toxic and induced immunological reactions [136]. Size-dependent adverse effects of silver NPs were found in in-vitro studies on hepatocytes indicating decreased mitochondrial function, lactate dehydrogenase (LDG) leakage and abnormal cell morphologies [137]. Influence of surface charge on the metallic NPs has also been addressed in the literature. Recently, dose-dependent effect on viability and capacity of nerve cells was seen in case of anionic MNPs [138]. Although in vivo findings on MNPs toxicity have also been reported, but majority of the data on the toxicity of MNPs have been the outcome of in vitro testing. It is promising that various efforts are being undertaken for reducing the uptake of NPs by macrophages (MPs) and to increase their accumulation at the active site through surface modification and/or incorporation of targeting ligands to the polymers/NPs [139-141]. On the basis of reports, the toxic

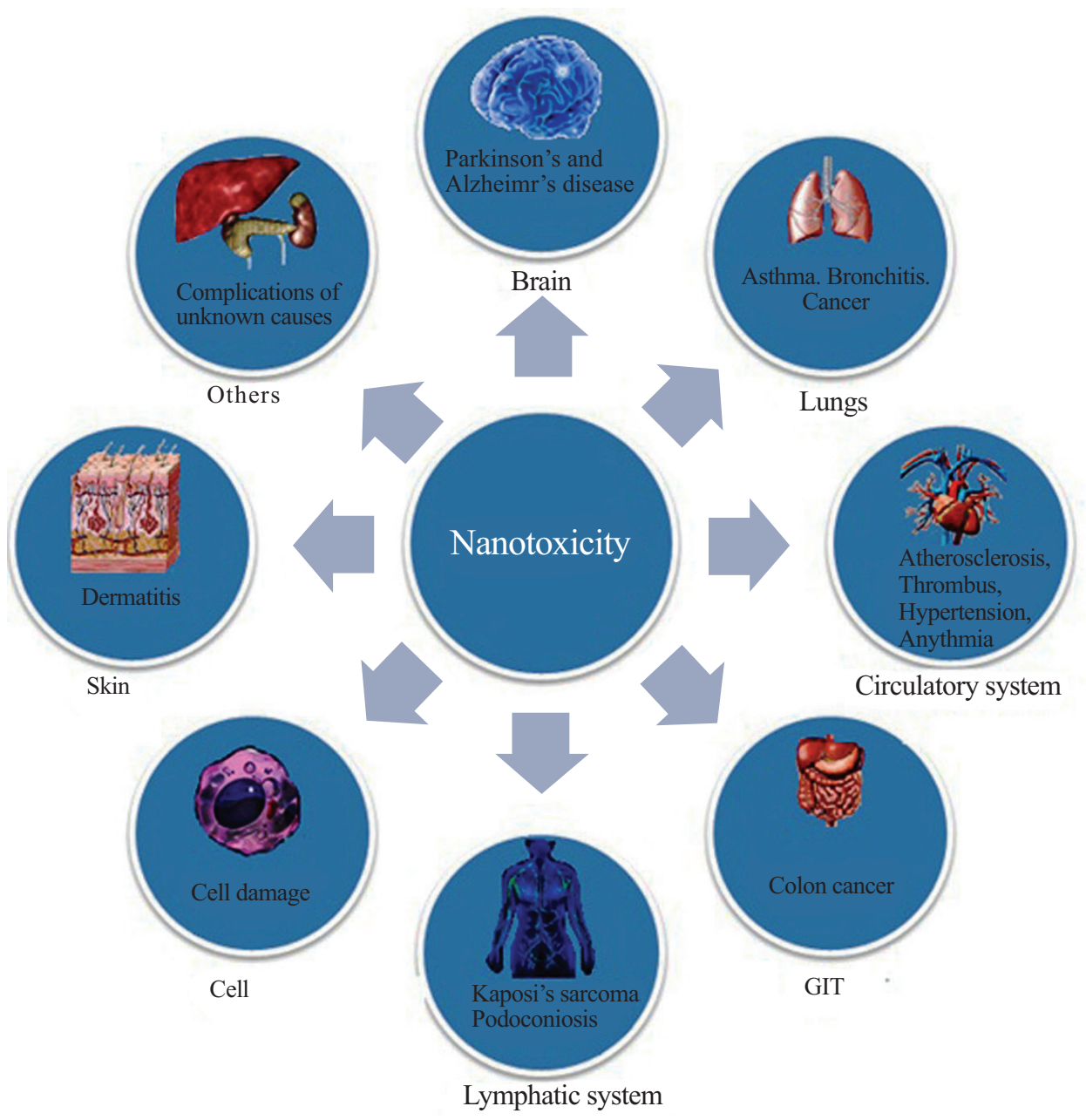

Fig. (3). Simplified pictorial diagram representing the possible toxic effects of nanomedicines on different body organs. 
effects of nanomedicines on different body organs are exemplified in Fig. (3). In nanomedicine formulation development, PEGylation is the most common technique used to make long circulating nano-carriers. Moreover, plenty of published papers on this subject indicate that such hydrophilic polymer coating reduces the nanoparticlesassociated toxicity. Regardless of the prevalent use of PEGylation for prolonging the circulation of nanomedicines, its mechanism for such action and interaction with biological system in the systemic circulation is not entirely clear. In fact, PEG has been shown to form a brush border over the nanomedicines' surface that leads to non-specific impermeable hindrances and sterically prevents access of tissue proteins [142]. Chain length, density, conformational freedom and flexibility of PEG are critical in making the nanomedicine-surface free from cellular interaction [143]. Although, such kind of coating provides non-specific shielding, but it was found that in case of PEGylated hexadecyl cyanoacrylate NPs, PEG was able to reduce the adsorption of ApoC and immunoglobulins, but not the other plasma proteins [144]. Similarly, with uncharged liposomes (made up of phosphatidylcholine and cholesterol) and negatively charged liposomes (made up of phosphatidic acid), coating with PEG-DSPE 2000 does not provide shielding from plasma protein adsorption [145]. Recently, several reports have been published that indicate the rapid clearance of PEGylated liposomes [146]. This effect is attributed to the formation of PEG-specific antibodies that prompt complement absorption [145]. Therefore, it should be noted that expression of specific antibodies to the particles or coating material may affect the pharmacokinetics, efficacy and safety of nanomedicines.

\section{Toxicity Assessment}

\section{In Vitro Cells and Gene-Based Toxicity}

To generate information on toxicity, studies at different levels (in vitro, in vivo and biochemical) must be carried out. Although in vitro studies may overcome the complexity of animal-based experiments, they may oversimplify processes and lack in vitro-in vivo correlation. However, they allow for a level of control well-suited for elucidating toxic effects and their mechanism at molecular level, which is extremely difficult to interpret in in-vivo studies. A gene-based approach (DNA strand breaks, chromosome damages and gene mutation, etc.) has the advantage of assessing toxicity at low-dose level and may detect carcinogenic effects which may not be monitored via classical cytotoxicity studies. The nature and mechanism of interaction between NPs, and molecular and cellular targets can be elucidated by TEM, SEM or X-ray-based microscopy.

\section{Oxidative Stress and Reactive Oxygen Species (ROS) Assessment}

Reduction of size to nano-scale leads to the conversion of normal particles to highly-active charged particles, which on interaction with cellular components and biological processes generate ROS, and produce oxidant injury. This paradigm may be used to evaluate the toxic potential of NPs [87]. Oxidative stress occurs when ROS production exceeds the defense capacity of the system and in such circumstances leads to damage of biomolecules like lipids, DNA, RNA, and proteins, resulting in excessive cell proliferation, apoptosis, and mutations. Metallic and inorganic NPs are known to induce oxidative stress through ROS generation during redox reaction by interruption of the electronic flux, perturbation of the permeability transition, and diminution of protective cellular component like glutathione [146-148]. ROS production can be monitored through ESR or with the use of fluorescent spectroscopy with or without quenchers such as furfuryl alcohol and superoxide dismutase. Furthermore, within a living cell this activity can be monitored through fluorescent microscopy or confocal microscopy. In addition, change in intracellular free calcium, mitochondrial function and structural integrity also serves as a tool to study ROS production and their associated oxidative stress.

\section{REGULATORY ASPECTS}

The positive impact of nanomedicines on the quality of life in life-threatening diseases like cancer is evident in clinical trials. However, applying these initial outcomes to clinical practice still needs to be rationalized and carefully controlled in terms of risk-to-benefit ratio, and is carefully overseen by regulatory authorities such as FDA, MHRA and EMEA. For any such products, the agencies have to set protocols that basically work for the assessment of three parameters: quality, safety and efficacy. The first generation of nanomedicines is already in clinical practice and some of it is now in the phase of generic development. Both generic manufacturers and regulatory agencies are struggling to finalize the studies that are required to demonstrate the bioequivalency of nanometric generic medicines compared to innovator products. This has been clearly demonstrated with several unproductive efforts in the generic development of nab-paclitaxel formulation. The claimed bio-similar of nabpaclitaxel, when evaluated, did not fit to reproduce particle size, stability, potency and other physicochemical attributes of nab-paclitaxel [149]. Moreover, unlike nab-paclitaxel, the reconstituted nanomedicine exhibited poor stability when evaluated for accelerated stability testing i.e. it formed aggregates within $24 \mathrm{~h}$ of study period. Pharmaceutical or chemical equivalence and/or bioequivalence may not sufficiently indicate the function of nanomedicines at the site of action, as assumed for standard conventional preparations. In addition, several liposomal formulations containing amphotericin B and doxorubicin have recently gone offpatent. The lack of critical information regarding composition, dimensional configuration of components and critical parameters that are essential for optimal performance of nanomedicines, raise concern about "generics" that may be approved based on conventional drug product standard and the guidelines but without having the same quality of the innovator. This exemplifies that how generic nanomedicine manufacturers and regulatory authorities are going to face challenges in the development and approval of such products. So, it is crucial that a comprehensive physicochemical based understanding of nanomedicines and recognition of critical parameters that affect their functioning be conducted early in developmental that will help regulatory bodies and industry in framing quality standard of nanomedicines products. Indeed, FDA has recently begun to consider relevant approval standards for generic copies of nanomedicines. A recently issued guideline in case of 
doxorubicin-loaded liposomal formulation $\left(\right.$ Doxil $\left.^{\circledR}\right)$ is an example for the generic development. Current scenarios illustrate that nanomedicines have defined their physicochemical characteristics but lack suitable pharmacokinetic models for such medicines. Considerations such as pathophysiology, target tissue, biodistribution and elimination, impact of their size and surface characteristics on organ, tissue and cellular localization, and better understanding of pharmacokinetics and pharmacodynamics correlations need to be addressed in experimental models. Moreover, quantitative techniques need to use for biodistribution studies of polymers and metals. In the context of polymeric and metallic nanomedicine therapeutics, carrier systems are developed with newer complex architectures (for example, dendrimers, quantum dots, SPIONs and multifunctional gold nanomaterials, etc.) and such carrier systems may be given by different route, viz pulmonary, i.v. and organ-directed injections. With the increased complexity of the architecture, induction of multifunctionality in a single carrier system frequently falls into a gap between medicines and medical devices regulation. It is to be noted that biological and medical devices assessment guidelines are based on general and non-specific standards. Moreover, a regulatory guideline addressing new nanometric devices and different category of medicines harmonized for the global regulatory will be highly productive.

\section{CONCLUSION}

In the current multidisciplinary arena, nanotechnology is in a distinctive status to transform cancer chemotherapy and diagnosis to produce a new generation of cancer therapeutics/theranostics (categorized as nanomedicines) with high sensitivity and precision for cancerous cells leading to reduction of the conventional therapeuticsassociated predictable toxicity. There are an increased number of FDA-approved cancer nanomedicines, their socio-environmental impact need to be addressed. While establishing the nanomedicines in clinical oncology practice, some key points need to be considered; toxicological data review of nanomedicines prior to use, in vivo-in vitro toxicity testing to understand the toxicity of new nanomedicines and its environmental impact.

\section{ABBREVIATIONS}

$\begin{array}{ll}\text { AML } & =\begin{array}{l}\text { Acute Myeloid Leukemia, Acute } \\ \text { Myelogenous Leukemia }\end{array} \\ \text { BBB } & =\text { Blood-Brain Barrier } \\ \text { CNTs } & =\text { Carbon nanotubes } \\ \text { CVD } & =\text { Chemical Vapor Deposition } \\ \text { DOX } & =\text { Doxorubicin } \\ \text { DPPC-DPPG } & =\text { Dipalmitoylphosphatidylcholine } \\ \text { EPR } & =\text { Dipalmitoylphosphatidylglycerol } \\ \text { HER2 } & =\text { Human Epidermal growth factor } \\ & \end{array}$

IGF- 1R = Insulin-like Growth Factor-1 Receptor

$\begin{array}{lll}\text { MDR: } & =\text { Multi Drug Resistance } \\ \text { MM } & =\text { Multi-walled Carbon Nanotubes } \\ \text { MWNT } & =\text { Nonionic Surfactant Based Vesicles } \\ \text { NSVs } & =\text { poly(alkyl cyanoacrylate) } \\ \text { PACA } & =\text { Polyamidoamine } \\ \text { PAMAM } & =\text { P-glycoprotein } \\ \text { PGP } & =\text { poly(lactic-co-glycolic acid) } \\ \text { PLGA } & =\text { Prostate-Specific Membrane Antigen } \\ \text { PSMA } & =\text { Reticuloendothelial System } \\ \text { RES } & =\text { Reactive Oxygen Species } \\ \text { ROS } & =\text { Single-walled Carbon Nanotubes } \\ \text { SWNT } & =\text { Theranostic Metallic Nanoparticle } \\ \text { TMNPs } & =\text { Tumor Necrosis Factor } \\ \text { TNF } & =\text { Vascular Endothelial Growth Factor } \\ \text { VEGF } & =\text { Vasoactive Intestinal Peptide } \\ \text { VIP } & =\text { Wheat-Germ Agglutinin } \\ \text { WGA } & =\text { Wheat-Germ Agglutinin Nanoparticles } \\ \text { WIT-NP } & \end{array}$

\section{CONFLICT OF INTEREST}

The author(s) confirm that this article content has no conflicts of interest.

\section{ACKNOWLEDGEMENTS}

The authors would like to acknowledge Ms. Neha Mallik and Mr. Mohd. Anwar for their valuable suggestion in improving quality of the manuscript.

\section{REFERENCES}

[1] Rahman, M.; Ahmad, M.Z.; Kazmi, I.; Akhter, S.; Afzal, M.; Gupta, G.; Ahmed, F.J.; Anwar, F. Advancement in multifunctional nanoparticles for the effective treatment of cancer. Expert Opin. Drug Deliv. 2012, 9 (4), 367-381.

[2] Youns, M.; Hoheisel, J.D.; Efferth, T. Therapeutic and diagnostic applications of nanoparticles. Curr. Drug Targets 2011, 12 (3), 357-365.

[3] Alexis, F.; Rhee, J.W.; Richie, J.P.; Radovic-Moreno, A.F.; Langer, R.; Farokhzad, O.C. New frontiers in nanotechnology for cancer treatment. Urol. Oncol. 2008, 26 (1), 74-85.

[4] Jain, K.K. Advances in the field of nanooncology. BMC Med. 2010, 13 (8), 83-91.

[5] Jain, R.K. Delivery of molecular medicine to solid tumors: lessons from in vivo imaging of gene expression and function. J. Control. Release 2001, 74(1-3), 7-25.

[6] Gao, Z.; Zhang, L.; Sun, Y. Nanotechnology applied to overcome tumor drug resistance. J. Control. Release 2012, 162(1), 45-55.

[7] Liu, Y.; Lu, W. Recent advances in brain tumor-targeted nano-drug delivery systems. Expert Opin. Drug Deliv. 2012, 9(6), 671-86.

[8] Perou, C.M.; Sorlie, T.; Eisen, M.B.; van de Rijn, M.; Jeffrey, S.S.; Rees C.A.; Pollack, J.R.; Ross, D.T.; Johnsen, H.; Akslen, L.A.; Fluge, O.; Pergamenschikov, A.; Williams, C.; Zhu, X.S.; Lønning, P.E.; Børresen-Dale, A.; Brown, O.P.; Botstein, D. Molecular portraits of human breasts tumors. Nature 2000, 406 (6797), 747752.

[9] Dhanasekaran, S.M.; Barrette, T.R.; Ghosh, D.; Shah, R.; Varambally, S.; Kurachi, K.; Pienta, K.J.; Rubin, M.A.; 
Chinnaiyan, A.M. Delineation of prognostic biomarkers in prostate cancer. Nature 2001, 412 (6849), 822-826.

[10] Shom, G.; Dan, G.; Duda, Lei. Xu.; Lance, L.; Munn, Yves. Boucher.; Dai, F.; Rakesh, K. J. Normalization of the vasculature for treatment of cancer and other diseases. Physiol. Rev. 2011, 91 (3), 1071-1121.

[11] Rapisarda, A.; Melillo, G. Role of the VEGF/VEGFR axis in cancer biology and therapy. Adv. Cancer Res. 2012, 114 (2), 237267.

[12] Davis, F.F. The origin of pegnology. Adv. Drug Deliv. Rev. 2002, 54 (19), 457-458.

[13] Moghimi, S.M.; Hunter, A.C. Poloxamers and poloxamines in nanoparticle engineering and experimental medicine. Trends Biotechnol. 2000, 18 (10), 412-420.

[14] Park, E.K.; Lee, S.B.; Lee, Y.M. Preparation and characterization of methoxy poly(ethylene glycol)/poly(epsilon-caprolactone) amphiphilic block copolymeric nanospheres for tumor-specific folate-mediated targeting of anticancer drugs. Biomaterials 2005, 26 (9), 1053-1061.

[15] Larsen, A.K.; Escargueil, A.E.; Skladanowski, A. Resistance mechanisms associated with altered intracellular distribution of anticancer agents. Pharmacol. Therapeutics. 2000, 85 (3), 217-229.

[16] Links, M.; Brown, R. Clinical relevance of the molecular mechanisms of resistance to anticancer drugs. Expert Rev. Mol. Med. 1999, 19(7), 1-21.

[17] Krishna, R.; Mayer, L.D. Multidrug resistance (MDR) in cancer mechanisms, reversal using modulators of MDR and the role of MDR modulators in influencing the pharmacokinetics of anticancer drugs. Eur. J. Pharm. Sci. 2000, 11(4), 265-283.

[18] Vauthier, C.; Dubernet, C.; Chauvierre, C.; Brigger, I.; Couvreur, P. Drug delivery to resistant tumors: the potential of poly(alkyl cyanoacrylate) nanoparticles. J. Control. Release 2003, 93 (2), 151160.

[19] Deverdiere, A.C.; Dubernet, C.; Nemati, F.; Soma, E.; Appel, M.; J. Fert, J.; Bernard, S.; Puisieux, F.; Couvreur, P. Reversion of multidrug resistance with polyalkylcyanoacrylate nanoparticles: towards a mechanism of action. Brit. J. Cancer 1997, 76 (2), 198205.

[20] Tsuruo, T. Molecular cancer therapeutics: recent progress and targets in drug resistance. Intern. Med. 2003, 42 (3), 237-243.

[21] Blagosklonny, M.V. Targeting cancer cells by exploiting their resistance. Trends Mol. Med. 2003, 9 (7), 307-312.

[22] Antony, A.C. The biological chemistry of folate receptors. J. Am. Soc. Hematol. 1992, 79 (21), 2807-2820.

[23] Lu, Y.; Low, P.S. Folate-mediated delivery of macromolecular anticancer therapeutic agents. Adv. Drug Deliv. Rev. 2002, 54 (5), 675-693.

[24] Sudimack, J.B.A.; Lee, R.J. Targeted drug delivery via the folate receptor. Adv. Drug Deliv. Rev. 2000, 41 (2), 147-162.

[25] Minko, T.; Dharap, S.S.; Pakunlu, R.I.; Wang, Y. Molecular targeting of drug delivery systems to cancer. Curr. Drug Targets 2004, 5 (4), 389-406.

[26] Rege, B.D.; Kao, J.P.Y.; Polli, J.E. Effects of nonionic surfactants on membrane transporters in Caco-2 cell monolayers. Eur. J. Pharm. Sci. 2002, 16 (27), 237-246.

[27] Pan J.; Feng, S.S. Targeted delivery of paclitaxel using folatedecorated poly (lactide) evitamin E TPGS nanoparticles. Biomaterials 2008, 29 (17), 2663-2672.

[28] Oyewumi, M.O.; Mumper, R.J. Influence of formulation parameters on gadolinium entrapment and tumor cell uptake using folate-coated nanoparticles. Int. J. Pharmaceutics. 2003, 251 (1-2), 85-97.

[29] Mehren, M.V.; Adams, G.P; Weiner, L.M. Monoclonal antibody therapy for cancer. Annu. Rev. Med. 2003, 54, 343-369.

[30] Kohler, G.; Milstein, C. Continuous culture of fused cell secreting antibody of predefined specificity. Nature 1975, 256, 495-497.

[31] Gu, F.X.; Karnik, R.; Wang, A.Z.; Alexis, F.; Levy-Nissenbaum, E.; Hong, S.; Langer, R. S.; Farokhzad, O.C. Targeted nanoparticles for cancer therapy. Nano Today 2007, 2, 14-21.

[32] Kocbek, P.; Obermajer, N.; Cegnar, M.; Kos, J.; Kristl, J. Targeting cancer cells using PLGA nanoparticles surface modified with monoclonal antibody. J. Control. Release 2007, 120, 18-26.

[33] Steinhauser, I.; Spankuch, B.; Strebhardt, K.; Langer, K. Trastuzumab modified nanoparticles: optimisation of preparation and uptake in cancer cells. Biomaterials 2006, 27, 4975-4983.
[34] Sievers, E.L.; Larson, R.A.; Stadtmauer, E.A.; Estey, E. Efficacy and safety of gemtuzumab ozogamicin in patients with CD33positive acute myeloid leukemia in first relapse. J. Clin. Oncol. 2001, 19, 3244-3254.

[35] Sievers, E.L.; Senter, P.D. Antibody-Drug Conjugates in Cancer Therapy. Annu Rev Med. 2012, DOI: 10.1146/annurev-med050311-201823.

[36] Alley, S.C.; Okeley, N.M.; Senter, P.D. Antibody-drug conjugates: targeted drug delivery for cancer. Curr. Opin. Chem. Biol. 2010, 14 (4), 529-537.

[37] Hurvitz, S.A.; Kakkar, R. The potential for trastuzumab emtansine in human epidermal growth factor receptor 2 positive metastatic breast cancer: latest evidence and ongoing studies. Ther. Adv. Med. Oncol. 2012, 4 (5), 235-245.

[38] Jung, G.; Grosse-Hovest, L.; Krammer, P.H.; Rammensee, H.G. Target cell-restricted triggering of the CD95 (APO-1/Fas) death receptor with bispecific antibody fragments. Cancer Res. 2001, 61 (5), 1846-1848.

[39] McCarron, P.A.; Marouf, W.M.; Quinn, D.J.; Fay, F.; Burden, R.E.; Olwill, S.A.; Scott, C.J. Antibody targeting of camptothecinloaded PLGA nanoparticles to tumor cells. Bioconjugate Chem. 2008, 19 (8), 1561-1569.

[40] Huh, Y.M.; Jun, Y.W.; Song, H.T.; Kim, S.; Choi, J.S.; Lee, J.H.; Yoon, S.; Kim, K.S.; Shin, J.S.; Suh, J.S.; Cheon, J. In vivo magnetic resonance detection of cancer by using multifunctional magnetic nanocrystals. J. Am. Chem. Soc. 2005, 127, 12387-12391.

[41] Akira, I.; Yuko, K.; Hiroyuki, H.; Hiroyuki, K.; Atsushi.; Yuji, W.; Takeshi, K. Magnetite nanoparticle-loaded anti-HER2 immunoliposome for combination of antibody therapy with hyperthermia. Cancer Lett. 2004, 212, 167-175.

[42] Chen, W.; Bardhan, R.; Bartels, M.; Perez-Torres, C.; Pautler, R.G.; Halas, N.J.; Joshi, A. A molecularly targeted theranostic probe for ovarian cancer. Mol. Cancer Ther. 2010, 9 (4), 10281038.

[43] Day, E.S.; Bickford, L.R.; Slater, J.H.; Riggall, N.S.; Drezek, R.A.; West, J.L. Antibody-conjugated gold-gold sulfide nanoparticles as multifunctional agents for imaging and therapy of breast cancer. Int. J. Nanomed. 2010, 9, 445-454.

[44] Lee, J.F.; Hesselberth, J.R.; Meyers, L.A.; Ellington, A.D. Aptamer database. Nucleic Acids Res. 2004, 32, 95-100.

[45] Wang, J.; Li, G. Aptamers against cell surface receptors: selection, modification and application. Curr. Med. Chem. 2011, 18 (27), 4107-4116.

[46] Gold, L.; Tuerk, C. Systematic evolution of ligands by exponential enrichment: RNA ligands to bacteriophage T4 DNA polymerase. Science 1990, 249, 505-510.

[47] Levy-Nissenbaum, E.; Radovic-Moreno, A.F.; Wang, A.Z.; Langer, R.; Farokhzad, O.C. Nanotechnology and aptamers: applications in drug delivery. Trends Biotechnol. 2008, 24, 442449.

[48] Mukerjee, A.; Ranjan, A.P.; Vishwanatha, J.K. Combinatorial nanoparticles for cancer diagnosis and therapy. Curr. Med. Chem. 2012, 19 (22), 3714-3721.

[49] Farokhzad, O.C.; Jon, S.; Khademhosseini, A.; Tran, T.T.; Lavan, D.A.; Langer, R. Nanoparticle aptamer bioconjugates: a new approach for targeting prostate cancer cells. Cancer Res. 2004, 64, 7668-7672.

[50] Yang, L.; Zhang, X.; Ye, M.; Jiang, J.; Yang, R.; Fu, T.; Chen, Y.; Wang, K.; Liu, C.; Tan, W. Aptamer-conjugated nanomaterials and their applications. Adv. Drug Deliver. Rev. 2011, 63 (14-15), 13611370 .

[51] Chong, V. Biological, preclinical and clinical characteristics of inhibitors of vascular endothelial growth factors. Ophthalmologica 2012, 227 (1), 2-10.

[52] Mousa, S.A. Anti-integrin as novel drug-discovery targets: potential therapeutic and diagnostic implications. Curr. Opin. Chem. Biol. 2002, 6, 534-541.

[53] Danhier, F.; Le Breton, A.; Préat, V. RGD-based strategies to target alpha (v) beta(3) integrin in cancer therapy and diagnosis. Mol. Pharmaceutics 2012, 9 (11), 2961-2973.

[54] Dufes, C.; Olivier, J.; Gaillard, F.; Gaillard, A.; Couet, W.J. Brain delivery of vasoactive intestinal peptide (VIP) following nasal administration to rats. Int. J. Pharmaceutics 2003, 255, 87-97.

[55] Wernig, K.; Griesbacher, M.; Andreae, F.; Hajos, F.; Wagner, J.; Mosgoeller, W.; Zimmer A. Depot formulation of vasoactive 
intestinal peptide by protamine-based biodegradable nanoparticles. J. Control. Release 2008, 130, 192-198.

[56] Torchilin, V.P. Targeted pharmaceutical nanocarriers for cancer therapy and imaging. AAPS J. 2007, 9, 128-147.

[57] Mezo, G.; Manea, M. Receptor-mediated tumor targeting based on peptide hormones. Expert Opin. Drug Deliv. 2010, 7 (1), 79-96.

[58] Dharap, S.S.; Wang, Y.; Chandna, P.; Khandare, J.J.; Qiu, B.; Gunaseelan, S.; Sinko, P.J.; Stein, S.; Farmanfarmaian, A.; Minko, T. Tumor-specific targeting of an anticancer drug delivery system by LHRH peptide. Proc. Natl. Acad. Sci. USA 2005, 102 (36), 12962-12967.

[59] Oussorena, C.; Elingb, W.M.C.; Crommelin, D.J.A. The influence of the route of administration and liposome composition on the potential of liposomes to protect tissue against local toxicity of two antitumor drugs. Biochim. Biophys. Acta. 1998, 1369, 159-172.

[60] Coimbra, M.; Crielaard, B.J.; Storm, G.; Schiffelers, R.M. Critical factors in the development of tumor-targeted anti-inflammatory nanomedicines. J. Control. Release 2012, 160 (2), 232-238.

[61] Schiffelers, R.M.; Koning, G.A.; ten Hagen, T.L.; Fens, M.H.; Schraa, A.J.; Janssen, A.P.; Kok, R.J.; Molema, G.; Storm, G. Antitumor efficacy of tumor vasculature-targeted liposomal doxorubicin. J. Control. Release 2003, 91 (1-2), 115-122.

[62] Gabizon, A.; Shmeeda, H.; Horowitz, A.T.; Zalipsky, S. Tumor cell targeting of liposome -entrapped drugs with phospholipid-anchored folic acid-PEG conjugates. Adv. Drug. Deliver. Rev. 2004, 56 (8), 1177-1192.

[63] Yokoe, J.; Sakuragi, S.; Yamamoto, K.; Teragaki, T.; Ogawara, K.; Higaki, K.; Katayama, N.; Kai, T.; Sato, M.; Kimura, T. Albuminconjugated PEG liposome enhances tumor distribution of liposomal doxorubicin in rats. Int. J. Pharmaceutics 2008, 353 (1, 2), 28-34.

[64] Riganti, C.; Voena, C.; Kopecka, J.; Corsetto, P.A.; Montorfano, G.; Enrico, E.; Costamagna, C.; Rizzo, A.M.; Ghigo, D. Bosia. A Liposome-encapsulated doxorubicin reverses drug resistance by inhibiting P-glycoprotein in human cancer cells. Mol. Pharmaceutics. 2011, 8 (3), 683-700.

[65] Akhter, S.; Kushwaha, S.; Warsi, M.H.; Anwar, M.; Ahmad, M.Z.; Ahmad, I.; Talegaonkar, S.; Khan, Z.I.; Khar, R.K.; Ahmad, F.J. Development and evaluation of nanosized niosomal dispersion for oral delivery of Ganciclovir. Drug Dev. Ind. Pharm. 2012, 38, 8492.

[66] Akhter, S.; Talegaonkar, S.; Khan, Z.I.; Jain, G.K.; Khar, R.K.; Ahmad, F.J. Assessment of ocular pharmacokinetics and safety of Ganciclovir loaded nanoformulations. J. Biomed. Nanotechnol. 2011, 7, 144-145

[67] Hong, M.; Zhu, S.; Jiang, Y.; Tang, G.; Pei, Y. Efficient tumor targeting of hydroxycamptothecin loaded PEGylated niosomes modified with transferrin. J. Control. Release 2009, 133 (2), 96102.

[68] Kataoka, K.; Matsumoto, T.; Yokoyama, M.; Okano, T.; Sakurai, Y.; Fukushima, S.; Okamoto, K.; Kwon, G.S. Doxorubicin-loaded poly(ethylene glycol)-poly(beta-benzyl-1-aspartate) copolymer micelles: their pharmaceutical characteristics and biological significance. J. Control. Release 2000, 64 (1-3), 143-153.

[69] Kwon, G.; Naito, M.; Yokoyama, M.; Okano, T.; Sakurai, Y.; Kataoka, K. Block copolymer micelles for drug delivery: loading and release of doxorubicin. J. Control. Release 1997, $48(2,3)$, 195-201.

[70] Kedar. U.; Phutane, P.; Shidhaye, S. Advances in polymeric micelles for drug delivery and tumor targeting. Nanomedicine 2010, 6, 714-729.

[71] Rapoport, N. Physical stimuli-responsive polymeric micelles for anti-cancer drug delivery. Progr. Polym. Sci. 2007, 32, 962-990.

[72] Mu, L.; Feng, S.S. A novel controlled release formulation for the anticancer drug paclitaxel $\left(\mathrm{Taxol}^{\circledR}\right)$ : PLGA nanoparticles containing vitamin E TPGS. J. Control. Release 2003, 86, 33-48.

[73] Gryparis, E.C.; Hatziapostolou, M.; Papadimitriou, E. Anticancer activity of cisplatin-loaded PLGA-mPEG nanoparticles on LNCaP prostate cancer cells. Eur. J. Pharm. Biopharm. 2007, 67, 1-8.

[74] Li, N.; Yang, X.; Zhai, G.; Li, L. Multifunctional pluronic/poly(ethylenimine) nanoparticles for anticancer drug $J$. Colloid Interf. Sci. 2010, 350, 117-125.

[75] Mo, Y.; Lim, L.Y. Preparation and in vitro anticancer activity of wheat germ agglutinin (WGA)-conjugated PLGA nanoparticles loaded with paclitaxel and isopropyl myristate. J. Control. Release $\mathbf{2 0 0 5}, 107,30-42$.
[76] Subedi, R.K.; Kang, K.W.; Choi, H.K. Preparation and characterization of solid lipid nanoparticles loaded with doxorubicin. Eur. J. Pharm. Sci. 2009, 37 (3-4), 508-513.

[77] De, M.; Ghosh, P.S.; Rotello, V.M. Applications of Nanoparticles in Biology. Adv. Mater. 2008, 20 (22), 4225-4241.

[78] Mukherjee, P.; Bhattacharya, R.; Mukhopadhyay, D. Gold nanoparticles bearing functional anti-cancer drug and antiangiogenic agent: a " 2 in 1" system with potential application in cancer therapeutics. J. Biomed. Nanotechnol. 2005, 1 (2), 224-228.

[79] Mukherjee, P.; Bhattacharya, R.; Wang, P.; Basu, S.; Nagy, J.A.; Atala, A.; Mukhopadhyay, D.; Soker, S. Antiangiogenic properties of gold nanoparticles. Clin. Cancer Res. 2005, 11 (9), 3530-3534.

[80] Curley, S.A.; Cherukuri, P.; Briggs, K.; Patra, C.R.; Upton, M.; Dolson, E.; Mukherjee, P. Noninvasive radiofrequency fieldinduced hyperthermic cytotoxicity in humancancer cells using cetuximab-targeted gold nanoparticles. J. Exp. Ther. Oncol. 2008, 7 (4), 313-326

[81] Patra, C.R.; Bhattacharya, R.; Mukhopadhyay, D.; Mukherjee, P. Fabrication of gold nanoparticles for targeted therapy in pancreatic cancer. Adv. Drug Deliver. Rev. 2010, 62 (3), 346-361.

[83] Ghosh, P.; Han, G.; De, M.; Kim, C.K.; Rotello, V.M. Gold nanoparticles in delivery applications. Adv. Drug Deliver. Rev. 2008, 60 (11), 1307-1315.

[83] Kim, C.K.; Ghosh, P.; Rotello, V.M. Multimodal drug delivery using gold nanoparticles. Nanoscale 2009, 1 (1), 61-67.

[84] Choi, C.H.; Alabi, C.A.; Webster, P.; Davis, M.E. Mechanism of active targeting in solid tumors with transferrin-containing gold nanoparticles. Proc. Natl. Acad. Sci. USA 2010, 107 (3), 1235-1240.

[85] Shen, Q.; Wang, X.; Fu, D. The amplification effect of functionalized gold nanoparticles on the binding of anticancer drug dacarbazine to DNA and DNA bases. Appl. Surf. Sci. 2008, 255 (2), 577-580.

[86] Cherukuri, P.; Glazer, E.S.; Curley, S.A. Targeted hyperthermia using metal nanoparticles. Adv. Drug. Deliver. Rev. 2010, 62 (3), 339-345.

[87] Akhter, S.; Ahmad, M.Z, Ahmad, I.; Singh, A.; Anwar, M.; Ahmad, F J.; Khar, R.K. Cancer targeted metallic nanoparticle: Targeting overview, recent advancement and toxicity concern. Curr. Pharm. Des 2011, 17 (18), 1834-1850.

[88] Ahmad, M.Z.; Akhter, S.; Jain, G.K.; Rahman, M.; Pathan, S.A.; Ahmad, F.J.; Khar, R.K. Metallic nanoparticles: technology overview \& drug delivery applications in oncology. Expert Opin. Drug Deliv. 2010, 7 (8), 927-942.

[89] Pankhurst, Q.A.; Connolly. J.; Jones, S.K.; Dobson, J. Applications of magnetic nanoparticles in biomedicine. J. Phys. D: Appl. Phys. 2003, 36 (13), R167.

[90] Jain, T.K.; Morales, M.A.; Sahoo, S.K.; Leslie-Pelecky, D.L.; Labhasetwar, V. Iron Oxide Nanoparticles for Sustained Delivery of Anticancer Agents. Mol. Pharmaceutics. 2005, 2 (3), 194-205.

[91] Yallapu, M.M.; Othman, S.F.; Curtis, E.T.; Gupta, B.K.; Jaggi, M.; Chauhan, S.C. Multi-functional magnetic nanoparticles for magnetic resonance imaging and cancer therapy. Biomaterials 2011, 32 (7), 1890-1805

[92] Maeng, J.H.; Lee, D.H.; Jung, K.H; Bae, Y.H.; Park, I.S.; Jeong, S.; Jeon, Y.S.; Shim, C.K.; Kim, W.; Kim, J.; Lee, J.; Lee, Y.M.; Kim, J.H.; Kim, W.H.; Hong, S.S. Multifunctional doxorubicin loaded superparamagnetic iron oxide nanoparticles for chemotherapy and magnetic resonance imaging in liver cancer. Biomaterials 2010, 31, 4995-5006.

[93] Zhuo, R.X.; Du, B.; Lu, Z.. In vitro release of 5-fluorouracil with cyclic core dendritic polymer. J. Control. Release 1999, 57 (3), 249-57.

[94] Gardikis, K.; Hatziantoniou, S.; Signorellib, M. Thermodynamic and structural characterization of Liposomal-Locked in-Dendrimers as drug carriers. Colloid Surface B 2010, 81 (1), 11-9.

[95] Iijima, S. Helical microtubules of graphitic carbon. Nature 1991 , 354 (6348), 56-58.

[96] Sinha, N.; Yeow, J.T. Carbon nanotubes for biomedical applications. IEEE Trans. Nanobioscience 2005, 4 (2), 180-195.

[97] Yan, Y.; Chan-Park, M.B.; Zhang, Q. Advances in CarbonNanotube Assembly. Small, 2007, 3 (1), 24-42.

[98] Liu, X.; Tao, H.; Yang, K.; Zhang, S.; Lee, S.T.; Liu, Z. Optimization of surface chemistry on single-walled carbon nanotubes for in vivo photothermal ablation of tumors. Biomaterials 2011, 32 (1), 144-151. 
[99] Chen, Z.; Pierre, D.; He, H.; Tan, S.; Pham-Huy, C.; Hong, H.; Huang, J. Adsorption behavior of epirubicin hydrochloride on carboxylated carbon nanotubes. Int. J. Pharmaceutics 2011, 405 (12), 153-161.

[100] Luo, G.; Long, J.; Zhang, B.; Liu, C.; Ji, S.; Xu, J.; Yu, X.; Ni, Q. Quantum dots in cancer therapy. Expert Opin. Drug Deliv. 2012, 9 (1), 47-58.

[101] Biju, V.; Itoh, T.; Ishikawa, M. Delivering quantum dots to cells: bioconjugated quantum dots for targeted and nonspecific extracellular and intracellular imaging. Chem. Soc. Rev. 2010, 39, 3031-3056.

[102] Bagalkot, V.; Zhang, L.; Nissenbaum, E.L.; Jon, S.; Kantoff, P.W.; Langer, R.; Farokhzad, O.C. Quantum Dot-Aptamer Conjugates for Synchronous Cancer Imaging, Therapy, and Sensing of Drug Delivery Based on Bi-Fluorescence Resonance Energy Transfer. Nano Lett. 2007, 7 (10), 3065-3070.

[103] Gao, X.; Chung, L.W.K.; Shuming, N.S. Quantum Dots for in vivo Molecular and Cellular Imaging. Methods Mol. Bio. 2007, 374 (III), 135-145.

[104] Li, Z.; Huang, P.; He, R.; Zhang, X.; Bao, C.; Ren, Q.; Cui, D. Aptamer-conjugated dendrimer-modified quantum dots for glioblastoma cells imaging. J. Phys. Conf. Ser. 2009, 188 (1), 012032.

[105] Chen, C.; Peng, J.; Xia, H.S. Quantum dots-based immunofluorescence technology for the quantitative determination of HER2 expression in breast cancer. Biomaterials 2009, 30 (15), 2912-2918.

[106] Ferry, D.R.; Traunecker, H.; Kerr, D.J. Clinical trials of Pglycoprotein reversal in solid tumors. Eur. J. Cancer 1996, 32A (6), 1070-1081.

[107] Pepin, X.; Attali, L.; Domrault, C.; Gallet, S.; Metreau, J.M.; Reault.; Cardot, P.J.; Imalalen, M.; Dubernet, C.; Soma, E.; Couvreur, P. On the use of ion-pair chromatography to elucidate doxorubicin release mechanism from polyalkylcyanoacrylate nanoparticles at the cellular level. J. Chromatogr. B. 1997, 702 (12), 181-191.

[108] Davis, M.E.; Chen, Z.G.; Shin, D.M. Nanoparticle therapeutics: an emerging treatment modality for cancer. Nat. Rev. Drug Discov. 2008, 7(9), 771-782.

[109] Schluep, T.; Hwang, J.; Cheng, J.; Heidel, J.D.; Bartlett, D.W.; Hollister, B.; Davis, M.E. Preclinical efficacy of the camptothecinpolymer conjugate IT-101 in multiple cancer models. Clin. Cancer Res. 2006, 12, 1606-1614.

[110] Northfelt, D.W.; Dezube, B.J.; Thommes, J.A.; Levine, R.; Von Roenn, J.H.; Dosik, G.M.; Rios, A.; Krown, S.E.; DuMond, C.; Mamelok, R.D. Efficacy of pegylated-liposomal doxorubicin in the treatment of AIDS-related Kaposi's sarcoma after failure of standard chemotherapy. J. Clin. Oncol. 1997, 15, 653-659.

[111] Lee, K.S.; Chung, H.C.; Im, S.A.; Park, Y.H.; Kim, C.S.; Kim, S.B.; Rha, S.Y.; Lee, M.Y.; Ro, J. Multicenter phase II trial of Genexol-PM, a Cremophor-free, polymeric micelle formulation of paclitaxel, in patients with metastatic breast cancer. Breast Cancer Res. Treat. 2008, 108, 241-250.

[112] Nemunaitis, J.; Cunningham, C.; Senzer, N.; Gray, M.; Oldham, F.; Pippen, J.; Mennel, R.; Eisenfeld, A. Phase I study of CT-2103, a polymer-conjugated paclitaxel, and carboplatin in patients with advanced solid tumors. Cancer Invest. 2005, 23, 671-676.

[113] Lukianova-Hleb, E.Y.; Hanna, E.Y.; Hafner, J.H.; Lapotko, D.O. Tunable plasmonic nanobubbles for cell theranostics. Nanotechnology 2010, 21 (8), 085102.

[114] Shubayev, V.I.; Pisanic, T.R.; Jin, S. Magnetic nanoparticles for theragnostics. Adv. Drug Deliver. Rev. 2009, 61 (6), 467-477.

[115] Shim, M.S.; Kim, C.S.; Ahn, Y.C.; Chen, Z.; Kwon, Y.J. Combined multimodal optical imaging and targeted gene silencing using stimuli-transforming nanotheragnostics. J. Am. Chem. Soc. 2010, 132 (24), 8316-8324.

[116] Rihova, B.; Riha, I. Immunological problems of polymer-bound drugs. Crit. Rev. Ther. Drug Carrier Syst. 1985, 1 (4), 311-374.

[117] Duncan, R. The dawning era of polymer therapeutics. Nat. Rev. Drug Discov. 2003, 2 (5), 347-360.

[118] Wang, B.; Feng, W.Y.; Wang, T.C.; Jia, G.; Wang, M.; Shi, J.W.; Zhang, F.; Zhao, Y.L.; Chai, Z.F. Acute toxicity of nano- and micro-scale zinc powder in healthy adult mice. Toxicol Lett. 2006, 161 (2), 115-123.

[119] Neerman, M.F.; Zhang, W.; Parrish, A.R.; Simanek, E.E. In vitro and in vivo evaluation of a melamine dendrimer as a vehicle for drug delivery.Int. J. Pharmaceutics 2004, 281 (1-2), 129-132.
[120] Meerum Terwogt, J. M.; ten Bokkel Huinink, W.W.; Schellens, J.H.; Schot, M.; Mandjes, I.A.; Zurlo, M.G.; Rocchetti, M.; Rosing, H.; Koopman, F.J.; Beijnen, J.H. Phase I clinical and pharmacokinetic study of PNU166945, a novel water-soluble polymer-conjugated prodrug of paclitaxel. Anti-cancer Drug 2001 12 (4), 315-323.

[121] Canesi, L.; Ciacci, C.; Betti, M.; Fabbri, R.; Canonico, B.; Fantinati, A.; Marcomini, A.; Pojana, G. Immunotoxicity of carbon black nanoparticles to blue mussel hemocytes. Environ. Int. 2008, 34, 1114-1119.

[122] Zhou, Y.; Yokel, R. The chemical species of aluminium influence its paracellular flux and uptake into Caco-2 cells, a model of gastrointestinal absorption. Toxicol. Sci. 2005, 87, 15-26.

[123] Lam, C.W.; James, J.T.; McCluskey, R.; Hunter, R.L. Pulmonary toxicity of single wall carbon nanotubes in mice 7 and 90 days after intratracheal instillation. Toxicol. Sci. 2004, 77, 126-134.

[124] Warheit, D.B.; Laurence, B.R.; Reed, K.L.; Roach, D.H.; Reynolds, G.A.; Webb, T.R. Comparative pulmonary toxicity assessment of single wall carbon nanotubes in rats. Toxicol. Sci. 2004, 77, 117-125.

[125] Lovric, J.; Cho, S.J.; Winnik, F.M.; Maysinger, D. Unmodified cadmium telluride quantum dots induce reactive oxygen species formation leading to multiple organelle damage and cell death. Chem. Biol. 2005, 12, 1227-1234.

[126] Sayes, C.M.; Gobin, A.M.; Ausman, K.D.; Mendez, J.; West, J.L.; Colvin, V.L. Nano-C60 cytotoxicity is due to lipid peroxidation. Biomaterials 2005, 26, 7587-7595.

[127] Kim, J.S.; Yoon, T.J.; Yu, K. N.; Kim, B.G.; Park, S.J.; Kim, H.W.; Lee, K.H.; Park, S.B.; Lee, J.K.; Cho, M.H. Toxicity and tissue distribution of magnetic nanoparticles in mice. Toxicol. Sci. 2006 , 89, 338-347

[128] Li, C.; Taneda, S.; Taya, K.; Watanabe, G.; Li, X.; Fujitani, Y.; Nakajima, T.; Suzuki, A.K. Effects of in utero exposure to nanoparticle-rich diesel exhaust on testicular function in immature male rats. Toxicol. Lett. 2009, 185, 1-8.

[129] Kwon, J.; Hwang, S.; Jin, H.; Kim, D.S.; Minai-Tehrani, A.; Yoon, H.J.; Choi, M.; Yoon, T.J.; Han, D.Y.; Kang, Y.W.; Yoon, B.I.; Lee, J.K.; Cho, M.H. Body distribution of inhaled fluorescent magnetic nanoparticles in the mice. J. Occup. Health 2008, 50, 1-6.

[130] Komatsu, T.; Tabata, M.; Kubo-Irie M.; Shimizu, T.; Suzuki, K.; Nihei, Y.; Takeda, K. The effects of nanoparticles on mouse testis Leydig cells in vitro. Toxicol. in vitro 2008, 22, 1825-1831.

[131] Alexiou, C.; Arnold, W.; Klein, R.J.; Parak, F.G.; Hulin, P.; Bergemann, C.; Erhardt, W.; Wagenpfeil, S.; Lübbe, A.S. Locoregional cancer treatment with magnetic drug targeting. Cancer Res. 2000, 60, 6641-6648.

[132] Braydich, S.L.; Hussain, S.M.; Schlager, J.; Hofmann, M.C. In vitro cytotoxicity of nanoparticles in mammalian germline stem cells. Toxicol. Sci. 2005, 88, 412-419.

[133] Browning, L.M.; Lee, K.J.; Huang, T.; Nallathamby, P.D. Lowman, J.E.; Xu, X.H. Random walk of single gold nanoparticles in zebrafish embryos leading to stochastic toxic effects on embryonic developments. Nanoscale 2009, 1, 138-152.

[134] De, J.W.H.; Borm, P. Drug delivery and nanoparticles: applications and hazards. Int. J. Nanomed. 2008, 3, 133-149.

[135] Chen, H.W.; Su, S.F.; Chien, C.T.; Lin, W.H.; Chen, J.J.W.; Pan, C.Y. Titanium dioxide nanoparticles induce emphysema-like lung injury in mice. FASEB J. 2006, 20 (130), 2393-2395.

[136] Yen, H.J.; Hsu, S.H.; Tsai, C.L. Cytotoxicity and immunological response of gold and silver nanoparticles of different sizes. Small 2009, 5, 1553-1561.

[137] Hussain, S.M.; Hess, K.L.; Gearhart, J.M.; Geiss, K.T.; Schlager, J.J. In vitro toxicity of nanoparticles in BRL $3 \mathrm{~A}$ rat liver cells. Toxicol. in vitro 2005, 19 (7), 975-983.

[138] Pisanic, T.R.; Blackwell, J.D.; Shubayev, V.I.; Fiñones, R.R.; Jin, S. Nanotoxicity of iron oxide nanoparticle internalization in growing neurons. Biomaterials 2007, 28, 2572-2581.

[139] Kirpotin, D.B.; Drummond, D.C.; Shao, Y.; Shalaby, M.R.; Hong, K.; Nielsen, U.B.; Marks, J.D.; Benz, C.C.; Park, J.W. Antibody targeting of long-circulating lipidic nanoparticles does not increase tumor localization but does increase internalization in animal models. Cancer Res. 2006, 66 (13), 6732-6740.

[140] Clift, M.J.; Rothen-Rutishauser, B.; Brown, D.M.; Duffin, R.; Donaldson, K.; Proudfoot, L.; Guy, K.; Stone, V. The impact of different nanoparticle surface chemistry and size on uptake and 
toxicity in a murine macrophage cell line. Toxicol. Appl. Pharmacol. 2008, 232 (3), 418-427.

[141] Wang, S.; Kim, G.; Lee, Y.E.; Hah, H. J.; Ethirajan, M.; Pandey, R.K.; Kopelman, R. Multifunctional biodegradable polyacrylamide nanocarriers for cancer theranostics--a "see and treat" strategy. ACS Nano. 2012, 6 (8), 6843-6851.

[142] Romberg, B.; Hennink, W.E.; Storm, G. Sheddable coatings for long-circulating nanoparticles. Pharm. Res. 2008, 25 (1), 55-71.

[143] Dos Santos, N.; Allen, C.; Doppen, A.M.; Anantha, M.; Cox, K.A.; Gallagher, R.C.; Karlsson, G.; Edwards, K.; Kenner, G.; Samuels, L.; Webb, M.S.; Bally, M.B. Influence of poly(ethylene glycol) grafting density and polymer length on liposomes: relating plasma circulation lifetimes to protein binding. Biochim. Biophys. Acta. 2007, 1768 (6), 1367-1377.

[144] Karmali, P.P.; Simberg, D. Interactions of nanoparticles with plasma proteins: implication on clearance and toxicity of drug delivery systems. Expert Opin. Drug Deliv. 2011, 8 (3), 343-357.

[145] Ishida, T.; Atobe, K.; Wang, X.; Kiwada, H. Accelerated blood clearance of PEGylated liposomes upon repeated injections: effect ofdoxorubicin-encapsulation and high-dose first injection. $J$. Control. Release. 2006, 115 (3), 251-258.

[146] Limbach, L.K.; Wick, P.; Manser, P.; Grass, R.N.; Bruinink, A.; Stark, W.J. Exposure of engineered nanoparticles to human lung epithelial cells: influence of chemical composition and catalytic activity on oxidative stress. Environ. Sci. Technol. 2007, 41 (11), 4158-4163.

[147] Xia, T.; Kovochich, M.; Brant, J.; Hotze, M.; Sempf, J.; Oberley, T.; Sioutas, C.; Yeh, J.I.; Wiesner, M.R.; Nel, A.E. Comparison of the abilities of ambient and manufactured nanoparticles to induce cellular toxicity according to an oxidative stress paradigm. Nano Letters 2006, 6 (8), 1794-1797.

[148] Akhter, S.; Ahmad, M.Z.; Ahmad, F.J.; Storm, G.; Kok, R.J. Gold nanoparticles in theranostic oncology: current state-of-the-art. Expert Opin. Drug Deliv. 2012, 9 (10), 1225-1243.

[149] Desai, N. Challenges in development of nanoparticle-based therapeutics. AAPS J. 2012, 14 (2), 282-295.

[150] Pasqualini, R.; Koivunen, E.; Kain, R.; Lahdenranta, J.; Sakamoto, M.; Stryhn, A.; Ashmun, R.A.; Shapiro, L.H.; Arap, W.; Ruoslahti, E. Amino peptidase $\mathrm{N}$ is a receptor for tumor-homing peptides and a target for inhibiting angiogenesis. Cancer Res. 2000, 60 (3), 722-727.

[151] Oh, P.; Borgstrom, P.; Witkiewicz, H.; Li, Y.; Borgstrom, B.J.; Chrastina, A.; Iwata, K.; Zinn, K.R.; Baldwin, R.; Testa, J.E.;
Schnitzer, J.E. Live dynamic imaging of caveolae pumping targeted antibody rapidly and speci fically across endothelium in the lung. Nat. Biotechnol. 2007, 25 (3), 327-337.

[152] Borisch, B.; Semac, I.; Soltermann, A.; Palomba, C.; Hoessli, D.C Anti-CD20 treat ments and the lymphocyte membrane: pathology for therapy. Verh. Dtsch. Ges. Pathol. 2001, 85, 161-166.

[153] Cirstoiu-Hapca, A.; Bossy-Nobs, L.; Buchegger, F.; Gurny, R.; Delie, F. Differential tumor cell targeting of anti-HER2 (Herceptin) and anti-CD20 (Mabthera) couple $\mathrm{d}$ nanoparticles, Int. J. Pharmaceutics 2007, 331 (2), 190-196.

[154] Graham, J.; Muhsin, M.; Kirkpatrick, P. Cetuximab. Nat. Rev. Drug Discov. 2004, 3 (7), 549-550.

[155] Fonsatti, E. Nicolay, H.J. Altomonte, M. Covre, A. Maio, M. Targeting cancer vas culature via endoglin/CD105: a novel antibody-based diagnostic and therapeutic strategy in solid tumors. Cardiovasc. Res. 2010, 86 (1), 12-19.

[156] Singh, R.P.; Agarwal, R. Tumor angiogenesis: a potential target in cancer control by phytochemicals. Curr. Cancer Drug Target. 2003, 3 (3), 205-217.

[157] Jubb, A.M.; Harris, A.L. Biomarkers to predict the clinical efficacy of bevacizumab in cancer. Lancet Oncol. 2010, 11 (12), 1172-1183.

[158] Ferguson, L.R.; Philpott, M. Cancer prevention by dietary bioactive components that target the immune response. Curr Cancer Drug Target. 2007, 7 (5), 459-464.

[159] Ren, J.; Agata, N.; Chen, D.; Li, Y.; Yu, W.H.; Huang L.; Raina D.; Chen, W.; Kharbanda, S.; Kufe, D. Human MUC1 carcinomaasso ciated protein confers resis- tance to genotoxic antic ancer agents. Cancer Cell 2004, 5 (2), 163-175.

[160] Ladewig, K.; Xu, Z.P.; Lu, G.Q. Layered double hydroxide nanoparticles in gene and drug delivery. Expert Opin. Drug Deliv. 2009, 6 (9), 907-922.

[161] Biao-xue, R.; Xi-guang, C.; Shuan-ying, Y.; Wei, L.; Zong-juan, M. EphA2-dependent molecular targeting therapy for malignant tumors. Curr. Cancer Drug Target. 2011, 11 (9), 1082-1097.

[162] Wang, Y.; Sun, Y. Insulin-like growth factor receptor-1 as an anticancer target: blocking transformation andinducing apoptosis. Curr. Cancer Drug Target. 2002, 2 (3), 191-197.

[163] Van der Veeken, J.; Oliveira, S.; Schiffelers, R.M.; Storm, G.; van Bergen En Henegouwen, P.M.; Roovers, R.C. Crosstalk between epidermal growth factor receptor- and insulin-like growth factor-1 receptorsignaling: implications for cancer therapy. Curr. Cancer Drug Target. 2009, 9 (6), 748-760. 